[Aus dem Staatlichen Hygienischen Institut zu Hamburg.]

(Direktor: Prof. Dr. Dunbar. Abteilungsvorsteher: Prof. Dr. Kister.)

\title{
Über die Beurteilung des Colibakterienbefundes im Trinkwasser nebst Bemerkungen über den Nachweis und das Vorkommen der Colibazillen.
}

\author{
Von
}

Oberarzt Dr. W. Fromme.

Inwieweit das Vorkommen von Colibazillen in einem zu Trinkzwecken benutzten Wasser als hygienisch bedenklich anzusprechen ist, wird zurzeit noch nicht einheitlich beurteilt. Das angeblich häufige, ja ubiquitäre Vorkommen der Colibazillen in der AuBenwelt hat rielfach die Ansichten zuungunsten ihrer ausschlieBlich intestinalen Herkunft unterstützt. Weiterhin ist zu berücksichtigen, daB in vielen Fällen der Zusammenhang. zwischen Colibefund und Fäkalverunreinigung fehlt. Bei der Zerstreuung fäkalischer Stoffe finden auch die Colibazillen eine weite Verbreitung; eine gewisse Anpassungsfähigkeit verleiht ihnen eine lange Zeit verbleibende Entwicklungsfähigkeit, so da $B$ es nicht überrascht, sie gelegentlich an Stellen zu finden, deren Verunreinigung durch Fäkalien zunächst ganz unwahrscheinlich ist.

Bei der Beurteilung von Colibefunden im Trinkwasser muß darüber uatürlich Einigkeit herrschen, ob der Colibacillus als ein spezifischer Darmbewohner gelten kann oder ob ihm etwa eine ubiquitäre Bedeutung zuhommt. Wesentlich zur Entscheidung dieser Frage ist seine Begriffsbestimmung. Die widersprechenden Ansichten beruhen zum goten Teil auf der Verschiedenheit der Untersuchungsmethode. Je enger der Begriff Coli gezogen wurde, um so seltener fand man den Bacillus in der AuBenwelt. Andererseits sorgten die verbesserten Methoden dafür, den Colinachweis in einer größeren Anzahl von Fällen zu führen. 
Im Laufe der letzten Jahre wurden am hiesigen Institut an fortlaufend eingehendem Material Untersuchungen über den Nachweis und das Vorkommen der Colibazillen angestellt, über die es sich lohnt, unter möglichster Berücksichtigung der Literatur einiges mitzuteilen. Weiterhin soll dann aber die vorliegende Arbeit, die auf Anregung von Herrn Professor Dunbar und unter wertvoller Unterstützung durch Herrn Professor Kister angefertigt wurde, einen Beitrag liefern zur Beurteilung des Colibazillenbefundes im Trinkwasser.

Uber den hier geübten Untersuchungsgang zum Nachweis von Colibazillen in Wasserproben seien folgende Angaben gemacht.

Von den zu untersuchenden Trinkwasserproben werden in der Regel $10 \mathrm{~cm}$, in einigen Fällen auch $200 \mathrm{~cm}$ angesetzt. Ist eine Verunreinigung des Wassers wahrscheinlich, wie z. B. bei Flußwässern und anderen Oberflächenwässern, so kommt eine Reihe jedesmal um das 10 fache verdünnter Lösungen zur Untersuchung. Mengen von $1^{\mathrm{ccm}}$ und weniger werden in Gärungsröhrchen gebraeht, die 1 prozentige Traubenzuckerpeptonbouillon enthalten. Diese Gärungsröhrchen bestehen aus einfachen Reagensröhrchen, in denen ein unten offenes kleineres Glasröhrchen steht. In dem blinden Ende dieses Röhrehens werden die sich entwickelnden Gasblasen aufgefangen. GröBere Wassermengen erhalten einen Zusatz einer 10 prozentigen Traubenzuckerpeptonkochsalzlösung, so daß eine 1 prozentige Lösung sich ergibt. Nach einer 24 stündigen Bebrütung bei $37^{\circ}$ werden 1 bis 2 ecr der angereicherten Probe von $10 \mathrm{cem}$ und mehr ebenfalls auf Gärungsröhrchen gebracht, um Gasbildung festzustellen. Tritt Gasbildung auf, so erfolgt Aussaat auf eine Endoplatte. Charalteristische, isoliert liegende Kolonien der Platte werden auf Agarröhrchen geimpft und dann weiter identifiziert. Als Colibakterien kommen in Betracht grammnegatire, Gelatine nicht verflüssigende Bakterien, die Traubenzucker vergären, Mileh zur Gerinnung bringen, Neutralrot reduzieren und auf DrigalskiConradi-Nährboden ein charakteristisches Wachstum zeigen.

Meistens bedient man sich zum Nachweise der Colibazillen in irgendeinem Medium einer Anreicherungsflüssigkeit. Eine groBe Zahl verschiedenster derartiger Flüssigkeiten sind angegeben worden. Von Vorteil werden die Methoden sein, die außer einer unbehinderten Entwicklung der Colibazillen eine Wachstumshemmung der Begleitbakterien bedingen. Vergleichende Untersuchungen über die Vermehrungsintensität ron Colibazillen in verschiedenen Nährflüssigkeiten sind von Saito (1) vorgenommen. 
Er verglich miteinander 1 promillige Phenolbouillon, 3 prozentiges Heuinfus, 2 prozentige Traubenzuckerbouillon, $2 \cdot 5$ prozentige und 5 prozentige $N$ ilchzuckerbouillon und 1 prozentige Dextrosebouillon. Das durchschnittliche Ergebnis von 3 Untersuchungen war nach einer bei $37^{\circ} 24$ Stunden währenden Bebrütung für $\mathbf{5}$ prozentige Milchzuckerbouillon die weitaus beste Zahl, nämlich eine Keimzunahme ron 1 auf 282 314. Nach dieser folgten: 1 prozentige Dextrosebouillon mit eiuer Vermehrung auf 144039 , in weiterem Abstande 2.5 prozentige Milchzuckerbouillon auf 25067 , Phenolbouillon auf 9744, 2 prozentige Traubenzuckerbouillon auf 9058 und schlieBlich Heuinfus auf 444 Keime. Die erhaltenen Werte der drei Paralleluntersuchungen Saitos sind jedoch ziemlichen Schwankungen unterworfen, z. B. 5 prozentige Milchzuckerbouillon 210474-95689540776 und 1 prozentige Dextrosebonillon entsprechend 288385-107725 -36008! Da die Ergebnisse zum Teil von unbeachteten Zufällen abhängig gewesen zu sein scheinen, dürfte es gewagt sein, 5 prozentige Milchzuckerbonillon einfach für geeigneter zu halten als 1 prozentige Dextrosebouillon. Jedenfalls erwiesen sich beide Nährflüssigkeiten als bei weitem vorteilhafter gegenüber den anderen, die zum Vergleich herangezogen worden.

Da mir die Wahl der Anreicherungsflüssigkeit für den Colinachweis besonders wichtig zu sein schien, habe auch ich folgende Nährflüssigkeiten untersucht.
1. 1 prozentige Dextrosebouillon
2. 5 prozentige Milchzuckerbouillon
3. 1 prozentige Laktosegalle
4. 3 prozentiges Heuinfús
5. 1 promillige Phenolbouillon
6. Bulirs Bouillon
7. Loefflers Paratyphuslösung
8. Äskulingallensalzbouillon
9. Ȧskulinbouillon
10. Mac Conkeys Bouillon.

Über die einzelnen Nährtlüssigkeiten, sowie ihre Herstellungsweise seien folgende Anmerkungen zur Orientierung gemacht:

7u 1. Die 1 prozentige Dextrosebouillon wurde in der bekannten zuerst ŕon Th. Smith (2) angegebenen Weise hergestellt (1 Prozent Dextrose, 1 Prozent Pepton, 0.5 Prozent $\mathrm{NaCl}$ ).

Zu 2. Die von Saito gerühmte 5 prozentige Milchzuckerbouillon, die ron v. Freudenreich (3) bei einer Temperatur von $35^{\circ}$ zuerst angewandt wurde, enthielt 1 Prozent Pepton, 5 Prozent Milchzucker und 0.5 Prozent $\mathrm{NaCl}$. 
Zu 3. Die Jacksonsche (4) Laktosegalle besteht aus Ochsengalle, der 1 Prozent Laktose zugefügt ist. Sie wird empfoblen von Prescott und Winslow (5) als "presumptive test", weiterhin von Sawin (6), Weston und Tarbett (7), Parker (8), Stokes und Stoner (9).

$\mathrm{Zu}$ 4. Lignières (10) Heuinfus war nach dem Rezepte von Kaiser hergestellt. Kaiser (11) hatte gute Erfahrungen mit einem 3 prozentigen Infus gemacht. 600 grm Heu (,süBes Heu') werden mit 5 Liter siedenden Leitungswasser übergossen und 15 Minuten darin belassen. Darnach wird das Heu ausgepreBt und das Wasser auf 5 Liter aufgefüllt. Nach Filtration Sterilisierung im Autoklaven während 1 Stunde. Nach Stehenlassen in der Kälte während 1-2 Tage, bis keine Präzipitate mehr entstehen, Filtration und Sterilisation. Kaiser fügte von diesem Infus dem zu untersuchenden Wasser so viel $\mathrm{zu}$, da $B$ das ganze Gemenge 3 prozentig wurde.

Zu 5. Die Anwendung der Phenolbouillon, von Chick (12) am besten in einer Konzentration von 1:1000 empfohlen, hat besonders in England eine weite Verbreitung gefunden. In $1000 \mathrm{~cm}$ Wasser sind $100{ }^{\mathrm{grm}}$ Dextrose, 50 grm Pepton und 1 grm Phenol enthalten.

Zu 6. Bulir (13) gibt zu 1 Teil Bouillon 2 Teile des zu untersuchenden Wassers. Die von mir benutzte Nährflüssigkeit enthält die Zusätze in den Mengenverhältnissen, die der mit Wasser verdünnteu Bouillon entsprechen. In 100 Teilen Wasser sind enthalten 35 Prozent Rindfleischextrakt, 0.8 Prozent Pepton, 0.5 Prozent $\mathrm{NaCl}, 1$ Prozent Mannit. Diese Mischung wird $1 \frac{1}{2}$ Stunden gekocht, danach mit Sodit neutralisiert, filtriert und im strōmenden Dampf 2 Stunden sterilisiert. Hinzu kommen dann 2 Prozent einer sterilisierten Wasserlösung von Neutralrot $(0.1$ Neutralrot in $100 \mathrm{~cm}$ destilliertem Wasser).

$\mathrm{Zu}$ 7. Die Loefflersche (14 und 15) Grünlösung II, später Paratyphuslösung bezeichnet, enthält in 100 Teilen Wasser 2 Teile Pepton, 5 Teile Hilchzucker, $1.5 \mathrm{~cm}$ einer Normalkalilösung, 1 Teil Nutrose und $3 \mathrm{cem}$ einer 0.2 prozentigen Lösung Malachitgrünkristalle (Chlorzinkdoppelsalz chemisch rein). Die Malachitgrünkristallösung sterilisierte ich für sich während 15 Minuten im strömenden Dampf und gab sie der fertigen Bouillon zu. Ich erwähne, daB Lopffler 1 cm Malachitgrünlösung hinzugibt und nicht $3^{\mathrm{cem}}$, wie bei Totsuka (16) erwähnt ist.

$\mathrm{Zu}$ 8. Die Äskulin-Gallensalzbouillon ist von Harrison und r. d. Leck (17) angegeben. Sie besteht aus 2 Prozent Pepton Witte, 0.5 Prozent Natr. taurochol., 0.1 Prozent Åskulin, 0.05 Prozent Eisenzitrat. Das Glykosid Äskulin wird durch die Colibazillen in Zucker und Äskuletin zerlegt, das sich mit dem Eisenzitrat verbindet und die Bouillon 
schwarz färbt. Diesen Test halten Harrison und v. d. Leck für besonders geeignet zum Colinachweis. Neuerdings lassen sie das Gallensalz fort, das angeblich gewisse Colistämme im Wachstum hindert.

Zu 9. Eine gallensalzfreie Bouillon nach Harrison und v. d. Leck.

Zu 10. Die Mac Conkeysche (18) Gallensalzbouillon ist in England viel im Gebrauch. $100^{\mathrm{eem}}$ neutrale Bouillon enthalten $0.5 \mathrm{grm}$ taurocholsaures Natrium, 2.0 $\mathrm{grm}$ Pepton, $0.5 \mathrm{grm}$ Glukose.

Den Vergleich der vorerwähnten Nährflüssigkeiten führte ich in der Weise durch, daB ich eine genau abgemessene Menge von $100^{\mathrm{com}}$ in einem Erlenmeyer-Kolben mit einer bestimmten Anzahl von Colibazillen beimpfte. Der verwandte Colistamm war frisch von einer mit Stuhl beimpften Endoplatte isoliert und von dieser einmal auf ein Agarröhrchen übertragen. Von einer Verdünnung von $1 / 100$, später $1 / 1000$ Ose einer etwa 20 stündigen Agarkultur wurde $1 \mathrm{com}$ den Versuchskolben zugesetzt. Aus der folgenden Zusammenstellung ist zu ersehen, dab ich auf diese Weise bei der ersten Keimzahlfeststellung ein im allgemeinen gut übereinstimmendes Ergebnis erhielt. Nach einer $37^{\circ}$ Bebrütung von 5, 12 und 24 Stunden wurden der gehörig durchschüttelten Flüssigkeit Proben zur Keimzählung entnommen. Die Verdünnungen erfolgten mit genau abgemessenen Mengen von $10^{\mathrm{cem}}$ physiologischer Kochsalzlösung, die Bebrütung der Gelatineplatten bei $22^{\circ}$ während 48 Stunden. Ich lasse nunmehr die Ergebnisse in der Reihenfolge der Versuche folgen. Der einzelne Versuch umfaBte die Prüfung von 4 Nährflüssigkeiten. Zum Vergleiche sind jedem Versuch die Zahlen der Vermehrungsintensität angefügt.

Versuch I ( $1 / 100$ Ose Colibazillen).

\begin{tabular}{|c|c|c|c|c|}
\hline & \multicolumn{4}{|c|}{ Keimzahlen } \\
\hline & $\begin{array}{l}1 \text { prozentige } \\
\text { Dextrose- } \\
\text { bouillon }\end{array}$ & $\begin{array}{l}5 \text { prozentige } \\
\text { Milchzncker- } \\
\text { bouillon }\end{array}$ & $\begin{array}{l}1 \text { prozentige } \\
\text { Laktosegalle }\end{array}$ & 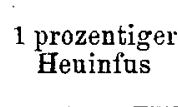 \\
\hline Sofort & 91000 & 115000 & 99000 & 98000 \\
\hline nach 5 Stunden & ca. 95700000 & 59100000 & 26410000 & 281000 \\
\hline, $12 \quad "$ & 479000000 & 194000000 & 46400000 & 61000000 \\
\hline " 24 & 5690000000 & 273000000 & 449000000 & 53000000 \\
\hline
\end{tabular}

Vermehrungsintensität

\begin{tabular}{cc|c|cc} 
Sofort & 1 & 1 & 1 & 1 \\
nach 5 Stunden & 1052 & 514 & 267 & 3 \\
$" 12 \quad$, & 5264 & 1687 & 469 & 622 \\
"24 " 24 & 62527 & 2374 & 4535 & 547
\end{tabular}


W. FROMME:

Versuch II (1/1000 Ose Colibazillen).

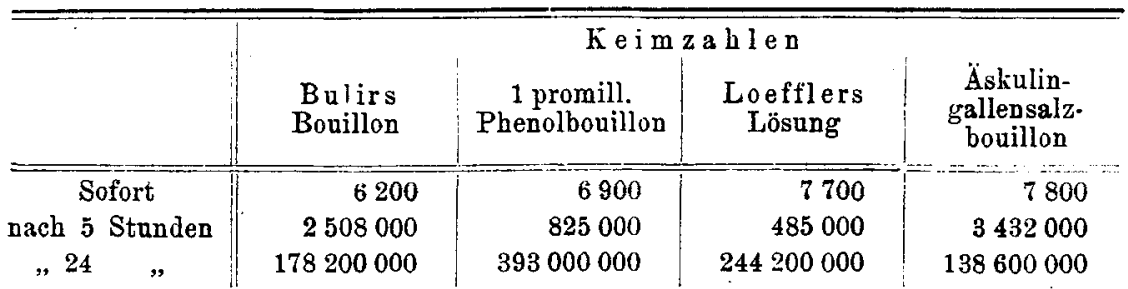

Vermehrungsintensität

\begin{tabular}{c|c|cc|c} 
Sofort & 1 & 1 & 1 & 1 \\
nach 5 Standen & 405 & 120 & 63 & 440 \\
, $24 \quad$, & 28742 & 56957 & 31714 & 17769
\end{tabular}

Versuch III (1/1000 Öse Colibazillen).

\begin{tabular}{|c|c|c|c|c|}
\hline & \multicolumn{4}{|c|}{ Keimzahlen } \\
\hline & $\begin{array}{c}1 \text { prozentige } \\
\text { Dextrosebouillon }\end{array}$ & $\begin{array}{l}\text { Bulirs } \\
\text { Bouillon }\end{array}$ & $\begin{array}{l}\text { Loeffilers } \\
\text { Lösung }\end{array}$ & Äskulinbouillon \\
\hline Sofort & 9200 & 8600 & 9300 & 9700 \\
\hline vach 5 Stunden & 790000 & 1980000 & 24800 & 2230000 \\
\hline , $12 \quad$, & 366000000 & 214000000 & 282000000 & 94000000 \\
\hline , $24 \quad$, & 484000000 & 270000000 & 474000000 & 99000000 \\
\hline
\end{tabular}

Vermehrungsintensität

\begin{tabular}{c|ccccc} 
Sofort & 1 & 1 & 1 & 1 \\
nach 5 Stunden & 86 & 230 & $2 \cdot 7$ & 230 \\
$\Rightarrow 12 \quad$, & 39783 & 24884 & 30323 & 8660 \\
$\Rightarrow 24 \quad$, & 52609 & 31465 & 50968 & 10260
\end{tabular}

Versuch IV (1/1000 Oัse Colibazillen).

\begin{tabular}{|c|c|c|c|c|}
\hline & \multicolumn{4}{|c|}{ Ke imzahlen } \\
\hline & $\begin{array}{c}1 \text { prozentige } \\
\text { Dextrosebouillon }\end{array}$ & $\begin{array}{c}1 \text { prozentige } \\
\text { Phenolbouillon }\end{array}$ & $\begin{array}{l}\text { Loefflers } \\
\text { Lösung }\end{array}$ & $\begin{array}{c}\text { Mac Conkey. } \\
\text { Bouillon }\end{array}$ \\
\hline Sofort & 6700 & 8800 & 8600 & 9100 \\
\hline nach 5 Stunden & 2320000 & 44000 & $<1000$ & 6000 \\
\hline , $12 \quad$ „, & 521000000 & 60000000 & 0 & 450000 \\
\hline „, 24 ', & 570000000 & 216000000 & $<100000$ & 7900000 \\
\hline
\end{tabular}

Vermehrungsintensitāt

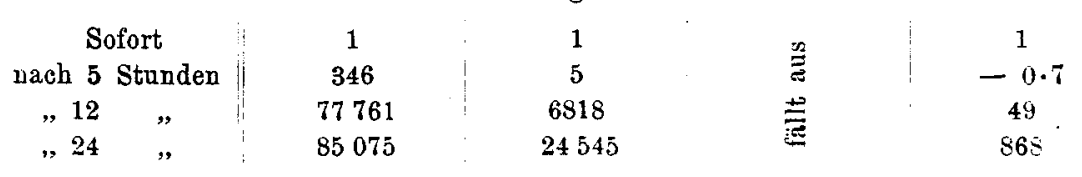


Versuch V (1/1000 Öse Colibazillen).

\begin{tabular}{|c|c|c|c|c|}
\hline & \multicolumn{4}{|c|}{ Keimzahlen } \\
\hline : & $\begin{array}{c}1 \text { prozentige } \\
\text { Dextrosebouillon }\end{array}$ & $\begin{array}{l}1 \text { prozentige } \\
\text { Phenolbouillon }\end{array}$ & $\begin{array}{l}\text { Loefflers } \\
\text { Lösung }\end{array}$ & $\begin{array}{c}\text { Mac Conkey - } \\
\text { Bouillon }\end{array}$ \\
\hline Sofort & 6800 & 10800 & 8900 & 8400 \\
\hline nach 5 Standen & 3030000 & 37000 & $2000 ?$ & 16000 \\
\hline , $12 \quad$, & 544000000 & 52000000 & $20000 ?$ & 460000 \\
\hline , 24 & 620000000 & 310000000 & $5800000 ?$ & 10100000 \\
\hline
\end{tabular}

Vermehrungsintensität.

\begin{tabular}{|c|c|c|c|}
\hline \begin{tabular}{c}
\multicolumn{3}{c}{ Sofort } \\
nach 5 Stonden \\
$\Rightarrow 12$ \\
$\Rightarrow 24$
\end{tabular} & $\begin{array}{c}1 \\
446 \\
80000 \\
91176\end{array}$ & $\begin{array}{c}1 \\
3 \\
4815 \\
28704\end{array}$ & 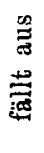 \\
\hline
\end{tabular}

Mit der 1 prozentigen Dextrosebouillon wurden durchgehend die besten Resultate erzielt. Es folgen dann Phenolbouillon und fast gleichwertig die Loefflersche Grünlösung (abgerechnet den Fehlsehlag in den Versuchsreihen IV und V) und weiterhin die Bulirsche Lösung, in weiterem Abstande erst Åskulingallensalzbouillon, Laktosegalle, 5 prozentige Milchzuckerbouillon, Mac Conkey-Bouillon, Heuinfus und Äskulinbouillon.

Vergleicht man die Schnelligkeiten der Vermehrung miteinander, so erscheint 1 prozentige Dextrosebouillon auch wiederum am günstigsten. Nach einer Bebrütungszeit von 5 Stunden erweist sich die Dextrosebouillon durchschnittlich am keimreichsten. Auffallend gering ist die Vermehrungsintensität nach dieser Zeit in der Loefflerschen Lösung. Beim Heuinfus wurde nach 24 Stunden eine geringere Keimzahl als nach 12 Stunden konstatiert.

Die Beurteilung dieser Zahlenergebnisse muB natürlich mit einer gewissen orsicht geschehen. Wenn auch die Qualität der Colibazillen innerhalb der einzelnen Versuche und auch ihre Anfangszahl ziemlich übereinstimmen, so dürfte die Keimzahlbestimmung so keimhaltiger Flüssigkeiten nur annähernde Werte ergeben. Immerhin scheint mir aus den Versuchen hervorzugehen, daB die l prozentige Dextrosebouillon in besonderem MaBe dem Wachstum der Colibazillen förderlich ist und daher als Anreicherungsflüssigkeit den Vorzúg verdient.

Was die Mengen der anzusetzenden Proben betrifft, so heben Prescott und Winslow (5) hervor, daB es nicht vorteilhaft ist, von einem Wasser, das in weniger als $1 \mathrm{ccm}$ Bacterium coli enthält, größere Quantitäten anzusetzen, da der Nachweis dann schwierig sei. So fanden Winslow und Hun newell (19), daB ron 48 sicher verunreinigten FluBZeitschr. f. Hygiene. LXV 
wasserproben in 18 Colibazillen nachgewiesen werden konnten, wenn $1^{\mathrm{ccm}}$ direkt in Dextrosebouillon bebrütet wurde, dagegen nur. 4 positive Diagnosen erzielt wurden nach Anreicherung von $100 \mathrm{~cm}$ in Phenolbouillon. ähnliche Erfahrungen hat Whipple (20) gemacht, der in 2.9 Prozent der untersuchten Wasserproben in einer Menge von $0.1^{\mathrm{ccm}}$ Colibazillen fand bei negativem Befund von 1.0 com, in 4.3 Prozent der Untersuchungen positiv in 0.1 und $1.0 \mathrm{~cm}$ bei negativem Ausfall von $10^{\mathrm{cmm}}$ Proben. Bei einer weiteren Untersuchungsreibe ergaben $10^{\mathrm{ccm}}$ Proben in 5.3 Prozent, $100^{\mathrm{ccm}}$ Proben in 4.7 Prozent und $500^{\mathrm{ccm}}$ Proben in 7.7 Prozent der Untersuchungen negativen Colibefund bei positivem Ausfall von kleineren Proben. Ebenso fand Saito (1), der sich der 5 prozentigen Milchzuckerbouillon als Anreicherungsflüssigkeit bediente, in einzelnen Fällen in gröBeren Wassermengen keine Colibazillen, obgleich kleinere Mengen ein positives Resultat ergeben hatten. Er erklärt diese Befunde damit, da $B$ in diesen Proben Colibakterien nur in geringer Menge vorhanden waren. Ähnliche Beobachtungen hat Marmann (21) gemacht.

Beim Vergleich einer Reihe eigener Untersuchungen im Hinblick auf den Colinachweis in verschiedenen Mengen ein und desselben Wassers hat sich herausgestellt, da $B$ gar nicht so selten der Nachweis in größeren Mengen miBglückt. Ein Unterschied besteht in dieser Beziehung zwischen weniger stark und den stark verunreinigten Wässern, indem letztere ungünstigere Aussichten geben, Colibazillen zu isolieren. Diese Verhältnisse vermag ich an einer Reihe von Badewässern zu erläutern, die in verschiedenen Stadien der Reinigung untersucht wurden. Das Reinwasser (Sandfiltratwasser mit ganz geringer Keimzahl) war in Gegensatz gestellt zum Rohwasser (Bassinwasser mit hoher Keimzahl). Von 209 Reinwasseruntersuchungen fielen $147=70.3$ Prozent colipositiv aus, und zwar $136 \mathrm{mal} 200^{\mathrm{cem}}, 43 \mathrm{mal} 10^{\mathrm{cem}}, 3 \mathrm{mal} 1^{\mathrm{cm}}$ Proben. Von diesen $147 \mathrm{coli}-$ positiven Proben wurden $8 \mathrm{mal}$ in einer Menge von $10^{\mathrm{cem}}$ bei negativem Ausfall der $200^{\mathrm{cm}}$ Probe, und $3 \mathrm{mal}$ in $1 \mathrm{~cm}$ bei negativem Ausfall der $10^{\mathrm{cm}}$ und $200^{\mathrm{ccm}}$ Probe Colibazillen gefunden. Also im ganzen fanden sich von 147 colipositiven Reinwasserproben $11=7.5$ Prozent, bei denen der Nachweis der zweifellos vorbandenen Colibazillen nicht gelang.

Anders verbalten sich im Gegensatz hierzu die Zahlen der Rohwasseruntersuchúngen. Unter diesen 223 Proben erwiesen sich 203 als colihaltig $=91$ Prozent, und zwar in einer Menge von 200.0, 10.0, 1.0 und $0.1 \mathrm{ccm}$ je $155,137,44$ bzw. 8 mal. Unter 203 colipositiven Rohwasserproben fiel die Coliuntersuchung $58 \mathrm{mal}=28.6$ Prozent negatir aus, obgleich in einer kleineren Menge desselben Wassers Colibazillen nachgewiesen worden waren. 
Stelle ich die nachweislich - auf Grund des colipositiven Befundes in einer kleineren Menge - colihaltigen Proben mit positivem und negativem Ergebnis gegenüber, so zeigt sich im einzelnen folgendes Bild. 81 in Mengen von 200.0 und $10.0 \mathrm{~cm}$ übereinstimmend colipositiven Proben stehen 36 Proben gegenüber, in denen sich $200.0 \mathrm{ccm}$ als negativ und $10.0 \mathrm{~cm}$ als positiv erwiesen, d. h. also in einer Henge von $200.0^{\mathrm{cm}}$ gelang in 30.9 Prozent der Fälle der Nachweis der im Wasser vorhandenen Colibazillen nicht.

Im Vergleiche hierzu ergab die Untersuchung des Reinwassers bei 36 positiven und 8 negativen Proben ein Verhältnis von 18.2 Prozent nicht gelungenen Nachweises.

Weiterhin, 19 in Mengen von 200.0, 10.0 und $1.0^{\mathrm{ccm}}$ übereinstimmend colipositiven Proben stehen 13 Proben gegenüber, in denen die Untersuchung sowohl von 200.0 als von $10^{\circ} 0^{\mathrm{ecm}}$ negativ, dagegen von $1.0^{\mathrm{cem}}$ positiv ausfiel, d. h. der Nachweis versagte in Mengen von 200.0 und $10.0^{\mathrm{ccm}}$ in 40.6 Prozent der Fälle. Beim Reinwasser wurden $3 \mathrm{mal}$ in 200.0 und $10.0 \mathrm{~cm}$ keine Colibazilllen gefunden, obgleich $1.0 \mathrm{~cm}$ die Bazillen enthielt.

Im Rohwasser schlieBlich versagte der Nachweis in 1.0, 10.0 und $200.0^{\mathrm{cen}}$ bei positivem Ausfall von $0.1 \mathrm{~cm}$ einmal, und einmal waren alle 4 Proben positiv. 5 mal gelang der Nachweis in $10.0 \mathrm{ecm}$ nicht bei positivem Befunde in $1.0 \mathrm{~cm}$, während $11 \mathrm{mal} 10.0$ und $1.0 \mathrm{~cm}$ positiv ausfielen. $3 \mathrm{mal}$ versagte er in $1.0^{\mathrm{cem}}$ bei negativer $0.1 \mathrm{~cm}$ Menge, während 5 mal 0.1 und $1.0^{\mathrm{cem}}$ beide Colibefunde ergaben.

Bei der Untersuchung des Reinwassers der Badeanstalt versagte mithin in 23.4 Prozent der Fälle (11 von 47) der Nachweis der in den Proben vorhandenen Colibazillen.

Im Bassinwasser der Badeanstalt miBlang es von 175 Untersuchungen $58 \mathrm{mal}$, Colibazillen zu isolieren. In 33.1 Prozent der Fälle also entgingen die Colibazillen der Untersuchung.

$\mathrm{DaB}$ in der Tat Colibazillen besonders in keimreichem Wasser dem Nachweise entgehen, zeigen auch eine Reihe in analoger Weise wie oben angestellter Elbwasseruntersuchungen. Die Resultate sind in folgender Tabelle kurz zusammengestellt (s. S. 260).

Unter den sicher colihaltigen Proben versagte also verhältnismäBig häufg' der Colinachweis. Die Prozentzahl des Elbwassers stimmt annähernd überein mit der des Rohwassers der Badeanstalt. Aus den Elbwasseruntersuchungen ergibt sich weiterhin, daß die Aussichten, Colibazillen zu isolieren, günstiger zu sein scheinen bei kleinen Mengen als bei großen. Eine Bestätigung dieser Beobachtung ist in dem Bericht über die Londoner Wasserversorgung 1908/09 enthalten. Houston (22) teilt in demselben 
Elbwasser

\begin{tabular}{|c|c|c|c|c|}
\hline \multirow{2}{*}{$\begin{array}{l}\text { Untersuchte Menge } \\
\text { in } \mathrm{ccm}\end{array}$} & \multirow{2}{*}{$\begin{array}{l}\text { Anzahl der coli- } \\
\text { haltigen Proben }\end{array}$} & \multicolumn{3}{|c|}{ Daron colinegativ } \\
\hline & & Anzahl & \multicolumn{2}{|c|}{ in Prozenten } \\
\hline 1000 & 52 & 25 & \multicolumn{2}{|c|}{$48 \cdot 1$ Prozent } \\
\hline 500 & 9 & 5 & $55 \cdot 5$ & $"$ \\
\hline 100 & 9 & 4 & $44 \cdot 4$ & $\because$ \\
\hline 50 & 55 & 20 & $36 \cdot 4$ &, \\
\hline 10 & 45 & 12 & $26 \cdot 7$ & $\eta$ \\
\hline 1 & 38 & 4 & 10.5 & , \\
\hline $0 \cdot 1$ & 18 & 3 & $16 \cdot 7$ &. \\
\hline 0.01 & 6 & 2 & \multicolumn{2}{|c|}{-} \\
\hline 0.001 & 1 & 1 & \multicolumn{2}{|c|}{-} \\
\hline Durchschnitt & 233 & 76 & \multicolumn{2}{|c|}{$32 \cdot 6$ Prozent } \\
\hline
\end{tabular}

eine Tabelle mit über die Häufigkeit des Colibazillenbefundes im New River (Keimzahl 1118), in der Themse (Keimzahl 2558) und im Lee River (Keimzahl 8794). In der folgenden Tabelle sind die positiven Colibefunde ron jedesmal 232 Untersuchungen in Prozentzahlen angegeben.

Colibefunde im FluBwasser.

\begin{tabular}{c||c|c|c}
\hline $\begin{array}{c}\text { Untersuchte Menge } \\
\text { in cem }\end{array}$ & New River & Themse & Lee River \\
\hline \hline 100 & 9.1 & 2.1 & 0.8 \\
10 & 40.9 & 10.3 & 5.2 \\
1 & 38.8 & 40.1 & 34.9 \\
0.1 & 8.2 & 36.6 & 38.8 \\
0.01 & 0.8 & 10.4 & 15.5 \\
0.001 & & 0.4 & 3.9 \\
0.0001 & & & 0.8
\end{tabular}

Die besten Resultate wurden mithin in $10 \cdot 0$ bis $0.1 \mathrm{~cm}^{\mathrm{cm}}$ Mengen erhalten, während die Untersuchung von $100^{\mathrm{ccm}}$ z. B. auffallend schlechte Ergebnisse hatte.

Weiter füge ich hier eine Zusammenstellung von auf Colibazillen untersuchten desinfizierten Abwasserproben an. Diese Proben beanspruchen vielleicht wegen der möglichen Schädigung der Bakterien, die durch die Desinfektion verursacht wurde, eine besondere Beurteilung.

$$
\text { Desinfizierte Abwasserproben. }
$$

\begin{tabular}{c|c|c|c}
\hline $\begin{array}{c}\text { Untersuchte Menge } \\
\text { in com }\end{array}$ & $\begin{array}{c}\text { Anzahl der coli- } \\
\text { haltigen Proben }\end{array}$ & \multicolumn{2}{c}{$\begin{array}{c}\text { Davon colinegativ } \\
\text { Anzahl }\end{array}$} \\
\hline 1000 & 125 & 44 & in Prozenten \\
50 & 121 & 44 & $35 \cdot 2$ \\
\hline Durchschnitt & 246 & 88 & $36 \cdot 4$ \\
\hline $\begin{array}{c}50 \text { und 1000 } \\
\text { gleichzeitig }\end{array}$ & 68 & 19 & $35 \cdot 8$ \\
\hline
\end{tabular}


DaB der Nachweis der Colibakterien in gröBeren Mengen dieser sehr verunreinigten Wässer schwieriger war als in keimreichen FluBwässern, ist nicht zu verwundern, wenn man annimmt, $\mathrm{da} B$ die Colibazillen von den Begleitbakterien überwuchert wurden.

Endlich berichte ich noch über einige Untersuchungen von Trinkwasserproben, deren Zahl nur gering ist, da wir hier verhältnismäBig selten Colibazillen im Trinkwasser finden. Es sind wiederum nur Proben verwertet, die nachweislich colihaltig waren. So konnten unter 12 Trinkwasserproben, die in einer Menge von $10^{\mathrm{com}}$ Colibazillen enthielten, $4 \mathrm{mal}$ d. h. in 33.3 Prozent, in der 20 mal so großen Menge keine Colibakterien gefunden werden.

Unter Zusammenfassung vorstehender Untersuchungen ergibt sich, daB der Colinachweis von 59 colihaltigen Reinwasserund Trinkwasserproben $15 \mathrm{mal}$, d. h. in 25.4 Prozent, von 654 colihaltigen Rohwasser-, FluBwasser- und Abwasserproben $222 \mathrm{mal}$, d. h. in 33.9 Prozent, mithin ron im ganzen 713 colihaltigen Proben $237 \mathrm{mal}$, d. h. in 33.2 Prozent versagte.

Dieses Ergebnis erscheint ungünstig und nicht gerade für die Brauchbarkeit der angewandten Untersuchungsmethode zu sprechen. Es bleibt aber zu berücksichtigen, daB, um zu vergleichbaren Zahlen zu gelangen, nur Proben herangezogen werden konnten, die nachweislich colihaltig waren. D. h. zur Gruppe der positiven Proben wurden nur solche gerechnet, die auch in der kleineren Menge desselben Wassers ein colipositives Ergebnis gehabt hatten, nicht aber die, welche nur in der in Vergleich gezogenen Menge colipositiv waren. So wurden z. B. von 52 Trinkwasserproben, angesetzt in Mengen von 200.0, 10.0 und $1.0 \mathrm{~cm}$, 40 gefunden, die nur in $200.0 \mathrm{cem}$ Colibazillen enthielten. Diese 40 Proben konnten bei einem Vergleich, der dartun sollte, wie häufig der Colinachweis in einer gröBeren Wassermenge im Gegensatz zur kleineren miBglückt, nicht verwandt werden. Proben, die bei Untersuchung von $10.0^{\mathrm{ecm}}$ colipositiv und von $200.0 \mathrm{~cm}$ colinegativ ausfielen, konnten daher nur mit den Proben verglichen werden, die sowohl in $200.0^{\mathrm{ccm}}$ als in $10.0^{\mathrm{cem}}$ sich positiv verhielten. Jene 40 somit nicht berücksichtigten Proben, in denen "ebenfalls der Colinachweis geführt wurde, würden das Verhältnis der positiven zu den negatiren Proben zugunsten der positiven verschieben. Es ist mithin berechtigt zu sagen, daB in Wirklichkeit der Colinachweis in colihaltigen Wässern weit häufiger gelingt, als die zahlenmäBige Berechnung ergibt, die nur die denkbar ungünstigsten Verhältnisse berücksichtigen konnte. 
Es liegt daher kein AnlaB vor, die bisherige Untersuchungsmethode zu verurteilen. Allerdings wird man sich bewubt bleiben müssen, daB die Methode in einer erwiesenen $Z a h l$ von Fällen zweifellos versagt. Dieser Nachteil wird zum Teil auf Kosten der unvermeidlichen Fehlerquellen zu setzen sein, die allen derartigen Untersuchungsmethoden anhaften. Wie weit andere praktisch brauchbare Methoden geeignet sind, das Überwuchern weniger Colibazillen durch die Begleitbakterien zu verhindern, sollen weitere Untersuchungen feststellen.

Wegen der schwierigen und zeitraubenden Diagnosenstellung der üblichen Untersuchungsmethode auf Colibazillen besteht der Wunsch nach einem einfachen und schnellen Verfahren zur Feststellung, ob ein Wasser verunreinigt ist oder nicht. Es fragt sich, ob die zu diesem Zwecke vorgeschlagenen Methoden, jene „presumptive tests", eine ausreichende Gewähr für eine richtige Beurteilung bieten. Als solcher Test wurde zunächst der Ausfall der Gasbildung in Dextrosebouillon empfohlen [Th. Smith (2)]. Eine Gasmenge von 25 bis 70 Prozent der Kapazität des geschlossenen Armes des Gärungsröhrchens galt als positiv. Das Gas soll zu etwa einem Drittel aus Kohlendioxyd, zu etwa zwei Drittel aus Wasserstoff bestehen. Zur Titerbestimmung dieses Testes wurden verschiedene Hiengen angesetzt. Diese Methode hat sich indes nicht bewährt. Wenn auch im allgemeinen ein negativer „,vorläufiger Test“ für die Güte eines Wassers sprechen wird, so kommt es doch verhältnismäBig häufig ror, daß ein positiver Ausfall, also Gasbildung, durch harmlose Schmarotzer hervorgerufen wird und nichts für eine stattgehabte Verunreinigung beweist. So fanden Winslow und Nibecker (23) unter 775 Proben, die aus 259 reinen Wässern stammten, 41 mal Gasbildung. Longle y und Baton (24) erhielten bei Untersuchung von 3553 Proben von Potomacwasser $794 \mathrm{mal}$ Gasbildung, während Colibazillen nur 529 mal, also nur in 67 Prozent der positiven "presumptive test".Zahlen nachgewiesen wurde. Gage (25) fand in 70 Prozent, Stokes und Stoner (9) in etwa 50 Prozent der positiven Gärungsröhrchen Colibazillen. Es gibt außer Colibazillen zahlreiche Dextrosevergärer [Jordan (40), Stokes und Stoner (9)]. Clark und Gage (26) stellten 58 Bakterienarten fest, - darunter 23 , die keine Ähnlichkeit mit der Coligruppe hatten —, die den „presumptive test" in Dextrosebouillon gaben. Mit Proben aus dem FluB Kennebec erhielt Whipple (27) allerdings ziemlich übereinstimmende Ergebnisse zwischen Gas- und Colitest. Es sei auch bemerkt, daB Stoughton (28), ferner Fuller und Ferguson (29), Stokes und Stoner (9) u. a. Colibazillen aus Proben nachwiesen, die zuvor keine Gasbildung gezeigt hatten.

Auch nach eigener Erfahrung eignet sich der Gastest nicht zur Beurteilung eines Wassers. Gastest in Dextrosebouillon und Colitest decken 
sich vielfach nicht. Wie häufig in Dextrosebouillon Gasbildung beobachtet wird, ohne daB der Colinachweis gelingt, ergibt sich aus Untersuchungen, die ich mit Wasserproben, die aus einer Badeanstalt herrührten, angestellt habe. Das gereinigte, durch Koks und Sand filtrierte Wasser ist für sich und das Bassinwasser ist für sich untersucht. Von 295 gasbildenden Reinwasserproben wurden nur $147 \mathrm{mal}$, also in 49.8 Prozent, Colibazillen gefunden. Der Gastest, verglichen mit dem Colitest des Rohwassers, verhielt sich wie 364:202, also nur in 55.5 Prozent deckten sich beide Befunde. Interessant ist ein Vergleich dieser Verhältnisse mit Rücksicht auf die untersuchten Wassermengen. In dieser Beziehung besteht kein wesentlicher Unterschied zwischen Reinwasser und Rohwasser. Im ganzen erwiesen sich von 659 gasbildenden Proben $349=53$ Prozent colipositiv, die sich folgendermaßen verteilen. Es waren Gas- und Colitest gleich

\begin{tabular}{|c|c|c|c|c|c|c|c|c|}
\hline n & $200 \cdot 0$ & $\mathrm{ccm}$ & von & 224 & Proben & $147=$ & 65. & Prozen \\
\hline$y$ & $10 \cdot 0$ & 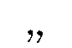 & , & 274 & $"$ & $144=$ & $52 \cdot 6$ & $"$ \\
\hline & $1 \cdot 0$ & " & , & 110 & $"$ & $48=$ & $43 \cdot 6$ & " \\
\hline & $0 \cdot 1$ & $"$ & $"$ & 35 & $"$ & $10=$ & $28 \cdot 6$ & \\
\hline & 0.01 & , & $"$ & 10 & $"$ & $0=$ & 0 & \\
\hline & 0.001 & $"$ & $n$ & 4 & $"$ & $0=$ & 0 & $"$ \\
\hline & 0.0001 & 1, & ", & 2 & $;$ & $0=$ & 0 & , \\
\hline
\end{tabular}

Es stellt sich also heraus, daß je größer die untersuchten Mengen, um so häufiger Gas- und Colitest übereinstimmen. In $1.0^{\mathrm{com}}$ Mengen wurde bei den Badewässern nur eine Koinzidenz von 43.6 Prozent gefunden. Die Badewässer haben also im Vergleich zu den Erfahrungen aus der Literatur auffallend häufig gasbildende Bakterien enthalten, die nicht als Colibazillen gedeutet werden konnten.

Eine in gleicher Weise angestellte Untersuchung von Elbwasser zeigt eine bessere Ubereinstimmung zwischen Gas- und Colitest und bestätigt im wesentlichen das, was bereits besonders von amerikanischer Seite festgestellt wurde. Von im ganzen 673 gasbildenden Proben wurden in $533=79.2$ Prozent Colibazillen nachgewiesen. Wie aus der nachfolgenden Tabelle zu ersehen ist, verhalten sich wiederum bei den in größeren Mengen angesetzten Proben Gas- und Colitest häufiger in Übereinstimmung als in kleineren Mengen.

Es waren Gas- und Colitest gleich:

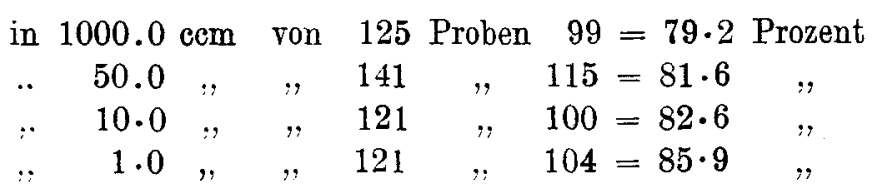




\begin{tabular}{|c|c|c|c|c|c|c|}
\hline in & $0.1 \mathrm{ccm}$ & von & 96 & Proben & $71=74.0$ & Prozent \\
\hline & 0.01, & , & 41 & , & $25=63.4$ & \\
\hline & 0.001 & , & 21 & , & $12=57 \cdot 1$ & \\
\hline & 0.0001, & , & 7 & , & $6=85 \cdot 7$ & , \\
\hline
\end{tabular}

In $1.0^{\mathrm{cm}}$ Mengen fallen hier im Gegensatz zu den Badewässern (43.6 Prozent) Gas- und Colitest in 85.9 Prozent der Fälle zusammen.

Es kann demnach als feststehend angesehen werden, daB Dextrose vergärende, nicht zur Coligruppe gehörige Bakterien häufig im Wasser gefunden werden und daB ihr Vorkommen nicht unbedingt zu einer Beanstandung des betreffenden Wassers führen darf.

Nach einigen neueren Untersuchungen allerdings scheint es, als ob die Jahreszeiten in der Weise auf die Häufigkeit der Gasbildner von EinfluB wären, als diese in der warmen Jahreszeit öfters gefunden werden als in der kalten, und daB weiterhin im Winter Gastest und Colitest regelmäBiger übereinstimmen als im Sommer. Mithin könnte der Gastest im Winter schon eher einen Anhaltspunkt für die Güte eines Wassers abgeben. Derartige Beobachtungen haben Winslow und Phelps (30) gemacht. Neuerdings kommt auch Houston (21) auf Grund auBerordentlich umfangreicher Versuche zu der Anschauung, daB das Verhältnis des ",presumptive test" und des Colitest in bemerkenswerter Weise von der Jahreszeit beeinflußt wird. Die Teste zeigen in den Wintermonaten einen deutlichen Parallelismus, im Sommer erhebliche Divergenzen. Der „presumptive test" könne demnach für den Winter einen guten Anhaltspunkt zur Beurteilung geben, nicht so im Sommer. Im allgemeinen hält Houston jedoch eine Feststellung der typischen Merkmale der Colibazillen für erforderlich.

Wieweit eine Ubereinstimmung des Gastestes und des Colitestes innerhalb der einzelnen Monate besteht, habe ich an der Hand von 673 Elbwasserproben festzustellen versucht. Das Ergebnis dieser Untersuchungen ist aus folgender Tabelle zu ersehen (s. S. 265).

Auch aus dieser Zusammenstellung läBt sich in ähnlicher Weise, wie Winslow und Phelps und Houston angeben, ersehen, daB in der Tat in den Wintermonaten Gas- und Colitest häufiger zusammenfallen als in den Sommermonaten. Ich glaube jedoch nicht, daraus die Berechtigung ableiten zu dürfen, auf eine vollständige Feststellung der Colidiagnose einstweilen verzichten $z \mathfrak{u}$ dürfen.

Da die Verwendung der Dextrosebouillon als vorläufiger Test nicht zu befriedigenden Ergebnissen führte, schlug Jackson (4) den Gebrauch von frischer Rindergalle vor, der 1 Prozent Laktose zugesetzt war. Wie 


\begin{tabular}{|c|c|c|c|c|c|}
\hline \multirow{2}{*}{ Mouate } & \multirow{2}{*}{$\begin{array}{c}\text { Zahl } \\
\text { der gas- } \\
\text { bildenden } \\
\text { Elbwasser- } \\
\text { proben }\end{array}$} & \multicolumn{2}{|c|}{ daron colipositiv } & \multicolumn{2}{|c|}{ Bei ausschlieBl. Berücksichtigung der } \\
\hline & & $\mathrm{Zahl}$ & $\stackrel{\text { in }}{\text { Prozenten }}$ & $\begin{array}{l}1000 \cdot 0,50 \cdot 0 \text { und } \\
10 \cdot 0 \mathrm{com} \cdot \text { Proben } \\
\text { in Prozenten }\end{array}$ & $\begin{array}{l}1.0 \text { bis } 0.0001 \\
\text { Proben in Prozenten }\end{array}$ \\
\hline Jali 08 & 31 & 13 & 41.9 & $6 \cdot 7$ & $75 \cdot 0$ \\
\hline August . & 32 & 14 & $43 \cdot 8$ & $46 \cdot 7$ & $41 \cdot 2$ \\
\hline September & 37 & 29 & $78 \cdot 4$ & $71 \cdot 4$ & $82 \cdot 6$ \\
\hline Oktober. & 45 & 40 & $88 \cdot 9$ & $100 \cdot 0$ & 79.2 \\
\hline November & 80 & 71 & 88.8 & $100 \cdot 0$ & $77 \cdot 5$ \\
\hline Dezember & 21 & 19 & $90 \cdot 5$ & $100 \cdot 0$ & $66 \cdot 6$ \\
\hline Januar 09 & 48 & 48 & $100 \cdot 0$ & $100 \cdot 0$ & $100 \cdot 0$ \\
\hline Februar . & 39 & 39 & $100 \cdot 0$ & $100 \cdot 0$ & $100 \cdot 0$ \\
\hline März . . & 36 & 22 & $61 \cdot 1$ & $73 \cdot 3$ & 0.0 \\
\hline April . & 15 & 15 & $100 \cdot 0$ & $100 \cdot 0$ & 0.0 \\
\hline Mai . & 36 & 20 & 55.6 & $44 \cdot 4$ & $88 \cdot 8$ \\
\hline Juni . & 26 & 19 & $73 \cdot 1$ & $83 \cdot 3$ & $64 \cdot 3$ \\
\hline Juli . & 25 & 21 & 84.0 & $93 \cdot 3$ & 70.0 \\
\hline August . & 31 & 23 & $74 \cdot 2$ & $66 \cdot 6$ & $81 \cdot 3$ \\
\hline September & 25 & 16 & $64 \cdot 0$ & $70 \cdot 0$ & $60 \cdot 0$ \\
\hline Oktober. & 48 & 46 & $95 \cdot 8$ & $100 \cdot 0$ & $90 \cdot 5$ \\
\hline November & 63 & 51 & 81.0 & $71 \cdot 8$ & $95 \cdot 7$ \\
\hline Dezember & 35 & 27 & $77 \cdot 1$ & $88 \cdot 2$ & $66 \cdot 6$ \\
\hline Zusammen & 673 & 533 & $79 \cdot 2$ & $81 \cdot 1$ & $76 \cdot 6$ \\
\hline
\end{tabular}

er neuerdings angibt, erweist sich eine Probe als positiv, also als colihaltig, wenn eine Gasmenge von 25 Prozent der Kapazität des geschlossenen Armes des Gärungsröhrchens nach spätestens 3 Tagen gebildet wird. Diese Methode hat Jackson (31) durchweg gute Dienste geleistet. Auf Grund teils eigener, teils von ihnen reranlaBter Untersuchungen kommen Prescott und Winslow (5) zu dem SehluB, daß die Jacksonsche Methode im Vergleich zur Dextrosebouillon in verunreinigten Wāssern einen höheren Prozentsatz positiver Ergebnisse und in Wasserproben guter Qualität einen geringeren Prozentsatz fälschlicherweise positiver Resultate gibt, Erfahrungen, die sich auch decken mit Untersuchungen von Sa win (32). Trotz gelegentlicher Fehlergebnisse halten sie die Verwendung der Laktosegalle für die zurzeit beste Schnellmethode, deren Ergebnisse gut übereinstimmen mit dem Urteil, das die vollständige Isolierung der Colibazillen abgibt. Auch Weston und Tarbett (7), ebenso Parker (8) hatten 'mit der Laktosegalle bessere Ergebnisse als mit Dextrosebouillon. Vergleichende Untersuchungen von Stokes und Stoner (9) ergaben bei Verwendung von Laktosegalle bezüglich der Übereinstimmung von Gasbildung und Colinachweis nur eine F'ehlergrenze von 10 Prozent. Allerdings wurden in 32 Prozent der Fälle Colibazillen gefunden, trotz ausbleibender Gasbildung! 
Von anderen Methoden, die eine schnelle Beurteilung einer Wasserprobe gestatten sollen, ist Rothbergers (33) Neutralrotbouillon zu erwähnen, die z. B. von Makgill (34), Savage (35) u. a., von Braun (36) mit Vorteil angewandt wurde, während Irons (37), Gage und Phelps (38) sie weniger für geeignet halten. Weiterhin ist die Neutralrotgallensalzbouillon von Grünba um und Hume (39) zu nennen, die von Savage (40), Harrison und v. d. Leck (17) empfohlen wird.

Stokes (41) empfiehlt eine Laktose-Neutralrotbouillon. Später jedoch gibt er auf Grund von mit Stoner (9) angestellten Versuchen der Liaktosegalle vor der Neutralrotbouillon den Vorzug.

Die Fähigkeit bei der gewöhnlichen Bruttemperatur von $37^{\circ}$ aus Dextrose Gas zu bilden, ist, wie wir gesehen haben, auBer den Colibazillen einer gröBeren Anzahl für die hygienische Beurteilung eines Wassers gleichgültiger Bakterien gemein. Es wird angenommen, daB bei Erhöhung der Bruttemperatur eine gewisse Auswahl stattfindet. Das Wachstum wird je nach dem den einzelnen Bakterien zuträglichsten Optimum bei zunehmender Temperatur früher oder später gehemmt. Warmblüterbakterien würden sich demnach bei einer Temperatur fortentwickeln, in der Bakterien, die an eine niedere Temperatur gewöhnt waren, nicht mehr gedeihen. So benutzte Vincent (42) eine Temperatur von $42^{\circ} \mathrm{bzw}$. $41 \cdot 5^{\circ}$. Rodet (43) weist darauf hin, dab die Ermittelung des Temperaturmaximums ein ausgezeichnetes Mittel zur Isolierung der Bakterien sei, und hat z. B. für die Isolierung der Typhusbakterien eine Temperatur von 45 bis $45.5^{\circ}$ vorgeschlagen. Eijkman (44) hat das Gasbildungsvermögen in Dextrosebouillon bei einer Temperatur von $46^{\circ}$ als Test dafür empfohlen, ob ein Wasser in bedenklicher Weise verunreinigt ist oder nicht. Er glaubt, daB mit wenigen Ausnahmen bei dieser Temperatur nur die für eine fäkale Verunreinigung sprechenden Colibazillen die Fähigkeit behalten, aus Dextrose Gas zu bilden. Eijkman bringt das zu untersuchende Wasser in Gärungskolben auf einen Prozentgehalt von etwa 1 Proz. Traubenzucker, 1 Prozent Pepton und 0.5 Prozent Kochsalz und bebrütet bei $46^{\circ}$. AuBer Eijkman selbst konnte auch Christian (45) an einer Reihe von Versuchen dartun, daß verunreinigte Wässer bei einer Bebrütung bei $46^{\circ}$ in Dextrosebouillon Vergärung zeigten, während sonst als einwandfrei zu bezeichnende Proben sich negativ verhielten. Christian sieht einen Vorzug der Gärungsprobe bei $46^{\circ}$ darin, da 3 eine Verunreinigung durch Kaltblüterfäces nicht angezeigt wird. Neumann (46), der am selben Institut wie Christian arbeitete, hält das elektive Moment der Methode für wertroll. DaB eine Vergärung als solche für das Vorhandensein von Colibazillen spreche, hält er jedoch noch nicht für bewiesen. Auf Grund 
freilich nicht sehr umfangreicher und z. T. unter künstlichen Verhältnissen angestellter Versuche spricht sich Thomann (47) in ähnlichem Sinne wie Christian günstig für die Methode aus. Nowack (48) schränkt den Wert der Methode ein, indem er nachwies, daß die von Eijłman angegebene Form nicht in allen Fällen mit Sicherheit die Abwesenheit von Bacterium coli beweist. Während das Wachstum der Colibazillen nicht ungünstig beeinfluBt wird, konnte beobachtet werden; dàB die Temperatur von $46^{\circ}$ Colibazillen hinsichtlich ihrer Gärfähigkeit meist wesentlich schädigt. Außerdem sei das Vermögen der Gasbildung bei $46^{\circ}$ bei den einzelnen Stämmen verschieden und abhängig von der Menge der ausgesäten Bazillen. Eben deswegen hält auch Kruse (49) die Methode für nicht empfindlich genug. Auch Vincent (50) kritisiert die Methode abfällig, weil einmal die Zuckerfermentation nicht bei allen Colistämmen gleich gat ausgebildet sei, und es viele andere bei böheren Temperaturen gasbildende Bakterien gäbe. Bei Versuchen, die Mallannah (51) am hiesigen Institut im Jahre 1906 ausführte, gaben von 32 Fischkotproben 14 Gasbildung bei $46^{\circ}$. Jedoch konnte aus keiner dieser 14 Proben ein coliähnliches Stäbchen gezüchtet werden. Worthmann (52) stellte, wie auch Eijkman angegeben hatte, fest, daB eine Reihe von allerdings als Fehlerquellen in der Praxis weniger in Betracht kommenden Bakterien, auBer Bacterium coli ebenfalls einen positiven Ausfall der Eijkmanschen Methode bedingen; er teilt im übrigen ungefähr den Standpunkt von Nowack. Nach Untersuchungen von Mordberg (53) gelang es nicht, in den wenigen Fällen, in denen Frosch- und Fischkot bei $46^{\circ}$ überhaupt Gas bildete, Colibazillen zu isolieren, dagegen rief Menschenkot stets Gärung hervor. Mordberg weist auf die quantitative und qualitative Veränderlichkeit aller Colikulturen gegenüber der $46^{\circ}$ Gärung hin. Gute Ergebnisse hatte im allgemeinen Lange (54) mit dem Verfahren. Das Ausbleiben von Gasbildung ist jedoch auch nach seinen Beobachtungen nicht beweisend für die Abwesenheit von Colibazillen, weshalb stets noch eine weitere Untersuchung folgen muB. Auch Reinsch (55) scheint die Eijkmansche Methode mit Vorteil zur Feststellung von Kaltblütercoli zu verwenden. In Versuchen, die Federolf (56) mit frisch aus Menschenkot gezüchteten Kulturen anstellte, versagte die Eijkmansche Reaktion unter Umständen. Nach Beobachtungen desselben Untersuchers soll der Ausfaŕ der Reaktion nicht abhängig sein von der Anzahl der Colibazillen.

Bulir (13) modifizierte die Eijkmansche Methode dahin, daB er an Stelle der Glukosebouillon eine mit Neutralrot versetzte Mannitbouillon nahm. Er vermeint auf diese Weise in 24 Stunden 4 charakteristische Eigenschaften des Bacterium coli feststellen zu können, Fähigkeit bei $46^{\circ}$ zu wachsen, Gas und Säure zu bilden, Neutralrot zu reduzieren. 
Neuerdings veröffentlicht Hilgermann (57) einen wertvollen Beitrag zur Frage der Beurteilung von Colibefunden im Trinkwasser und kommt auch ausführlich auf die Fijkmansche Gärungsprobe zu sprechen. Die aus seinen Wasserproben gewonnenen Colistämme ließen sich je nach ihrem Gärvermögen bei $46^{\circ}$ in zwei Gruppen teilen. Es stellte sich heraus, daB Colibazillen, welche Gärung bei $46^{\circ}$ geben, nur im verunreinigten Wasser gefunden wurden, d. h., aus Wasserentnahmestellen stammten, die auf Grund ihrer örtlichen Liage, des balteriologischen oder chemischen Befundes als nicht einwandfrei anzusehen waren. Colibazillen, die biologisch und morphologisch von „echten" Colibazillen nicht zu unterscheiden waren, aber bei $46^{\circ}$ keine Gärung gaben, wurden auch in einwandfreiem Wasser nachgewiesen. Hilgermann hält diese letztere Gruppe der Colibazillen, da sie nicht aus dem Warmblüterorganismus stammen, für die Beurteilung der Güte eines Wassers ohne jede Bedeutung. In 10 Prozent hatte die Eijkmansche Gärungsprobe versagt. In diesem Falle wäre der sekundäre Eijkman nach Nowack (48) anzusetzen oder eine Identifizierung der aus der Anreicherungsflüssigkeit gewonnenen Colistämme auch auf Gärfähigkeit bei $46^{\circ}$ anzustellen. Eine weitere Identifizierung der aus der Gärungsflüssigkeit gewonnenen Colibazillen hält er für selbstverständlich. Einige Male beobachtete Hilgermann ein Ausbleiben der Gasbildung, obgleich die weitere Untersuchung die Anwesenheit typischer, bei $46^{\circ}$ vergärender Colibazillen ergab. Er nimmt an, daB die Anzahl der rorhandenen Colibazillen für das Auftreten der Gärung zu gering gewesen sei.

Man wird sagen dürfen, daß die bisherigen in der Literatur vorhandenen Mitteilungen der Eijkmanschen Methode im allgemeinen kein ablehnendes Urteil ausstellen. Die von Eijkman angegebene Form wird jedoch von den meisten Autoren nicht für ausreichend erachtet, um über das Vorhandensein von Colibazillen $z \mathfrak{u}$ entscheiden. Die Notwendigkeit einer weiteren kulturellen Identifizierung nimmt der Methode aber gerade den Vorzug der Einfachheit vor anderen Methoden.

Um zu einem eigenen Urteil über den Wert der Eijkmanschen Probe zu gelangen, habe ich verschiedene Wege der Untersuchung eingeschlagen. Auf die Frage, ob es überhaupt wünschenswert und berechtigt erscheint, zwischen Warmblütercoli und Kaltblütereoli zu unterscheiden, séi weiter unten eingegangen. Angenommen es sei unberechtigt, so könnte immerhin die Bebrütung bei $46^{\circ}$ eine elektive Methode darstellen, die besonders in keimreicheren Wässern unter Zurückdrängung der Begleitbakterien Colibazillen zur Isolierung gelangen lieBe, die bei der $37^{\circ}$ Bebrütung überwuchert wären. Es müBte zunächst festgestellt werden, inwieweit der Colibacillus selbst bei der Temperatur von $46^{\circ}$ beein- 
flußt wird. Ich habe daher eine vergleichende Untersuchung angestellt mit verschiedenen Nährflüssigkeiten, die unter sonst ganz gleichen Bedingungen einerseits bei $37^{\circ}$, andererseits bei $46^{\circ}$ bebrütet wurden.

Die Anordnung der Versuche deckt sich mit der am Anfang dieser Arbeit wiedergegebenen. Ich gehe deswegen hier nicht näher darauf ein. Jedem Versuche folgen die Angaben der Wachstumsintensität (s. S. 270 und 271).

Demnach ist bei $46^{\circ}$ nach den ersten 5 Stunden gegenüber der Temperatur von $37^{\circ}$ zumeist eine erhöhte Vermehrungsintensität zu beobachten. Nacb 12 Stunden ist eine weitere Zunahme erfolgt, bei der aber die Temperatur von $37^{\circ}$ ein weit besseres Resultat gibt, als die von $46^{\circ}$. Nach einem 24 stündigen Aufenthalt in einer Temperatur von $46^{\circ}$ ist eine nur geringe Zunahme, bzw. starke Abnahme gegenüber dem Befunde der 12 Stunden früher erfolgten Untersuchung festzustellen, während die $37^{\circ}$ Temperatur weiterhin eine erhebliche Keimzunahme bedingte. Das Ergebnis fällt sehr zuungunsten der $46^{\circ}$ Bebrütung aus, wenn man die 24 stündigen Ergebnisse von $46^{\circ}$ und $37^{\circ}$ vergleicht.

Diese unterschiedlichen Resultate sind so zu erklären, daB die Entwicklung der Colibazillen bei einer Temperatur von $46^{\circ}$ geschädigt wird. Übrigens fand auch v. Benczur (58), daB Colibazillen selbst bei $43^{\circ}$ sich zwar noch entwickeln, jedoch wesentlich spärlicher als bei den gewöhnlichen Temperaturen von 35 und $37^{\circ}$. Es ist mithin auch anzunehmen, daB die Bebrütung von $46^{\circ}$ Colibazillen, die aus Wasserproben gezüchtet werden sollen, im Gegensatz zu einer Bebrütung bei $37^{\circ}$ schädigt. Wachstum und Nachweis der Colibazillen bei einer Temperatur von $46^{\circ}$ dürfte besonders ersohwert sein, wenn es sich um Colibazillen handelt, die ohnehin in ihrer Lebensfähigkeit geschädigt sind, wie auch Mordberg (53) mit Recht hervorhebt.

Soweit diese Versuche ergeben, scheint mir somit die Eijkmansche Methode die an ein Nährmedium zu stellenden Bedingungen, die ein unbehindertes Wachstum der Colibazillen gewährleisten, nicht zu erfüllen.

Andere Versuche erstreckten sich auf die praktische Verwendung der Methode beim Nachweis von Colibazillen. Ich untersuchte z. B. den Darminhalt von 16 Fischen, die in der Stadt von einem Fischhändler bezogen 'waren. 6 mal trat Gasbildung bei $46^{\circ}$ auf. AuBer diesen 6 auch bei nachfolgender Untersuchung als colihaltig erwiesenen Proben wurden aus zwei weiteren Röhrchen, die keine Gasbildung angezeigt hatten, ebenfalls Colibazillen isoliert. Einmal lieferte die $46^{\circ}$ Bebrütung ein colipositives Ergebnis, obgleich bei der parallelen $37^{\circ}$ Bebrütung keine Colibazillen gefunden wurden. 
W. Fromme:

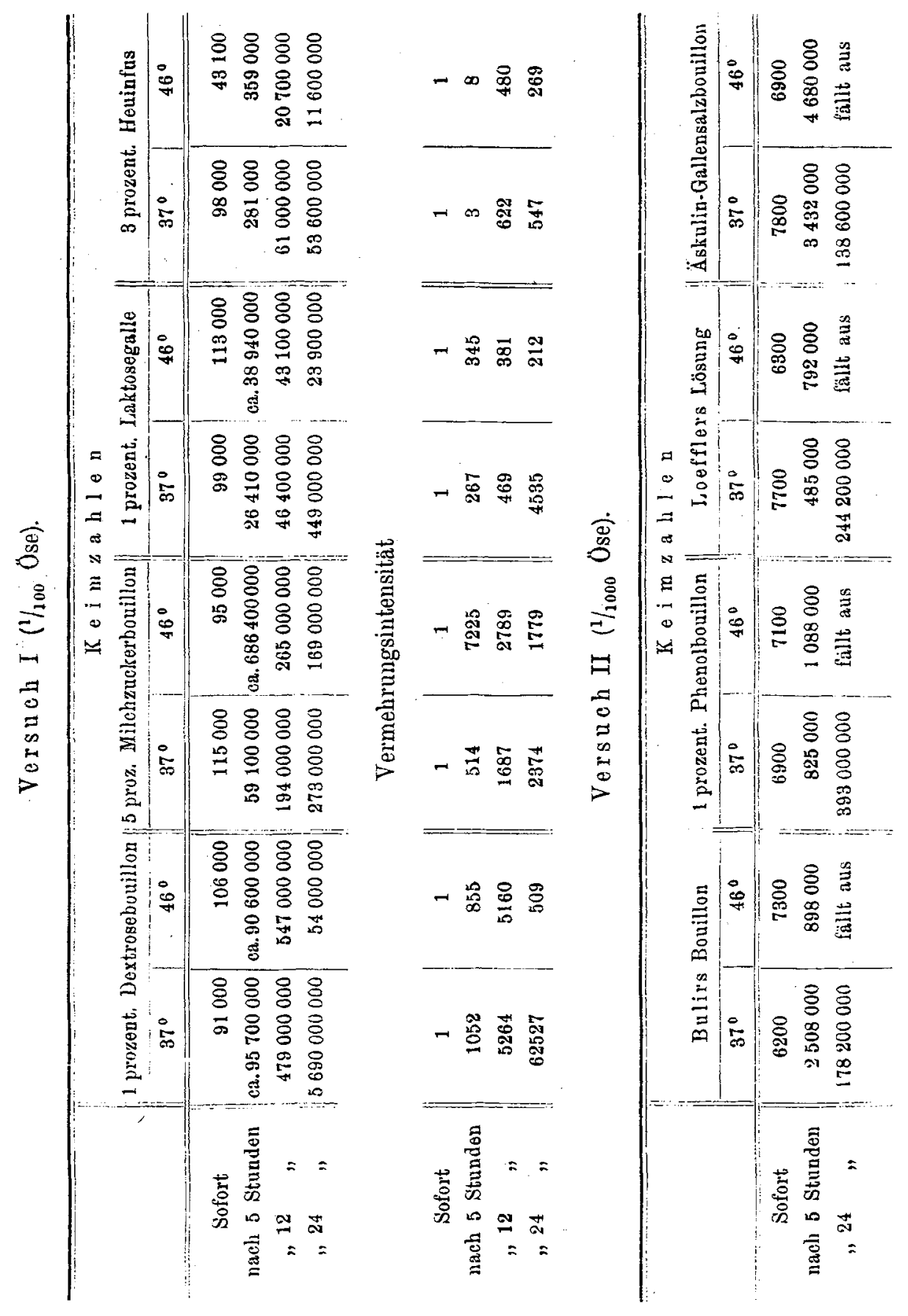


Übek Colibakterien im Trinkwasser.

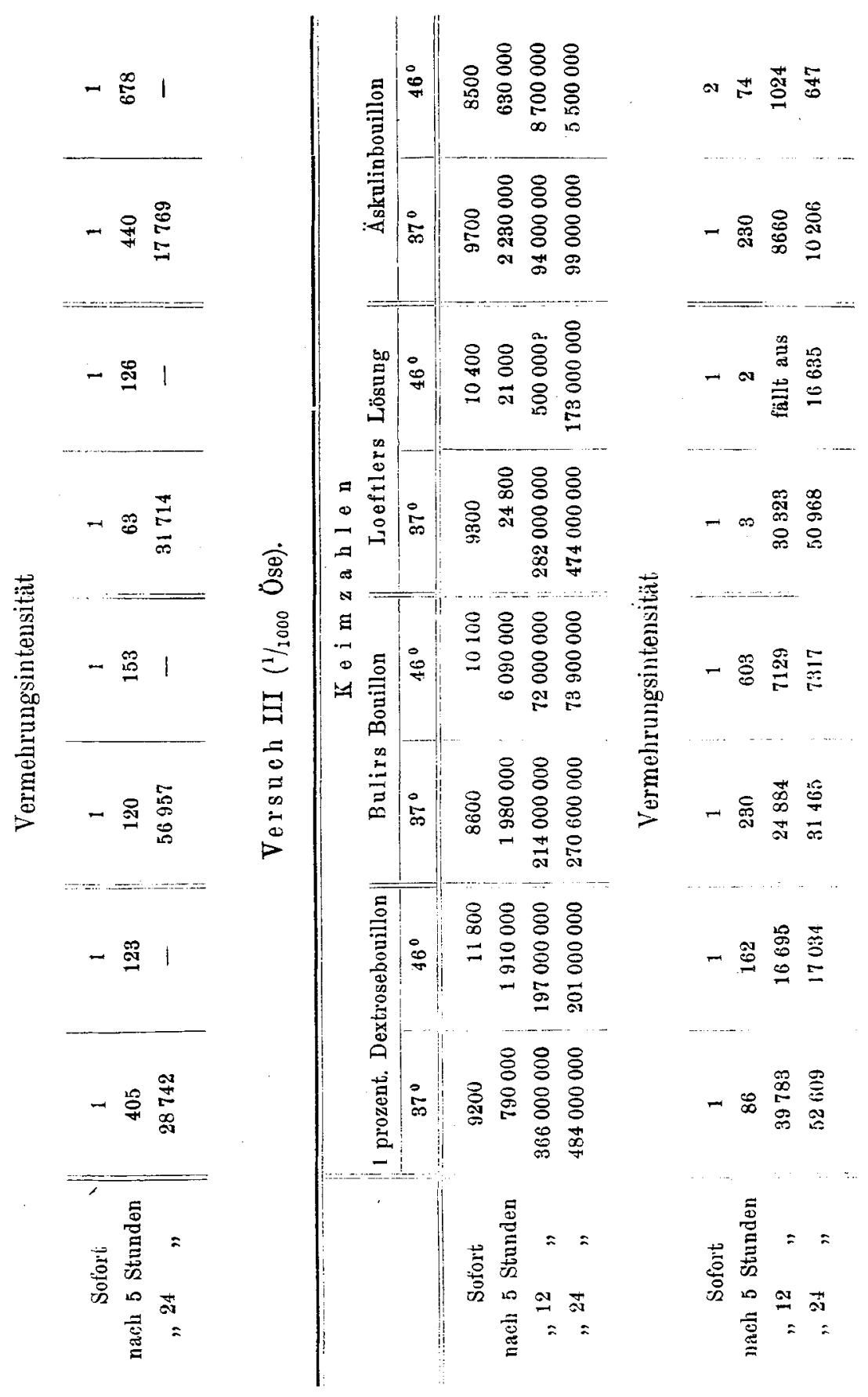


Eine rergleichende Colititerbestimmung von 36 Elbwasserproben bei 46 und $37^{\circ}$ ergab eine nur geringe Differenz der Titerverhältnisse. Die Bebrütung bei $46^{\circ}$ sollte eigentlich geringere Titer erwarten lassen, da hier das Fehlen der sogenannten Kaltblütercolibazillen zum Ausdruck kommen müBte. Das Ergebnis der Versuche ist in folgender Tabelle, in der die Häufigkeit der Titerbefunde eingefügt ist, zusammengestellt.

\begin{tabular}{c|c|c}
\hline Titer & bei $37^{\circ}$ & bei $46^{\circ}$ \\
\hline 10.0 & - & 2 \\
1.0 & 11 & 12 \\
0.1 & 12 & 11 \\
0.01 & 7 & 7 \\
0.001 & 6 & 4
\end{tabular}

Eine weitere vergleichende Colititerbestimmung bei $37^{\circ}$ und $46^{\circ}$ von allerdings nur 14 colihaltigen Trinkwasserproben, von denen in der Regel Mengen von $200.0,10.0,1.0,0.1$ und 0.01 angesetzt waren, zeigte folgende Verhältnisse. 2 mal stimmten die Colititer bei $37^{\circ}$ und $46^{\circ}$ überein, $14 \mathrm{mal}$ wurden bei $37^{\circ}$ allein und $2 \mathrm{mal}$ bei $46^{\circ}$ allein Colibazillen gefunden.

Was die Häufigkeit der Gasbildung bei $46^{\circ}$ ohne nachherigen Colibefund, also anderer thermophiler Vergärer anlangt, so sei erwähnt, daB unter 36 Elbwasserproben 5 mal, d. h. in etwa 14 Prozent Gasbildung konstatiert wurde ohne Colibefund, unter den 14 Trinkwasserproben nur 2 mal und zwar in verschiedener Menge ein nnd derselben Probe.

Im praktischen Gebrauch hat sich also auch hier die Eijkmansehe Methode als nicht ausreichend sicher erwiesen. Ausbleibende Gasbildung. spricht nicht gegen Colibalterien, Gasbildung ist nicht durchaus beweisend für Colibakterien. Andererseits $m u B$ bemerkt werden, daB die Bebrütung bei $46^{\circ}$ gelegentlich zum Ziele führt, wo die Bebrütung bei $37^{\circ}$ versagt.

Diese Untersuchungen wie auch die in der Literatur mitgeteilten Erfahrungen bestimmen mich za der Ansicht, daB die Eijkmansche Methode nicht die Bedeutung für den Nachweis ron Colibazillen im Wasser verdient, die ihr vielfach beigelegt wird. Sie ausschlieblich für die Entscheidung über das Vorhandensein von Colibazillen gelten zu lassen, ist unzulässig. Allein als Anreicherungsmethode kann sie in Betracht gezogen werden. Es ist jedoch zu berücksichtigen, daB die Temperatur von $46^{\circ}$ oberhalb des Temperaturoptimums für Colibazillen liegt und daß eine Temperatur von $37^{\circ}$ für Colibazillen günstigere Wachstumsbedingungen bietet. Immerhin scheint die Methode dann gute Dienste zu leisten, wenn die durch 
die Temperatur von $46^{\circ}$ bedingte Wachstumshemmung in stärkerer Weise die Begleitbakterien als die Colibazillen betrifft, und diese dann unter Umständen als Reinkulturen auf den Platten wachsen. Solche Verbältnisse sind besonders bei an Begleitbakterien reichen Wässern zu erwarten, der Colinachweis dürfte allerdings nur bei Anwesenheit zahlrejcher Colibazillen gelingen. Die wenigen Fälle, in denen die $46^{\circ}$ Methode allein zum Ziele führt, treten indes zurück gegenüber den Fällen, in denen allein bei einer Bebrütung von $37^{\circ}$ Colibazillen isoliert werden. Ich halte es deshalb nicht für angezeigt, die $37^{\circ}$ Methode zugunsten einer Bebrütung bei $46^{\circ} \mathrm{zu}$ verlassen.

Vincent (42) bediente sich zur Bebrütung der Anreicherungsflüssigkeit (Karbolbouillon) einer Temperatur von $42^{\circ}$. Auch bei dieser Temperatur sind hier einige vergleichende Untersuchungen mit der gewöhnlichen Bebrütung bei $37^{\circ}$ angestellt worden. Von 48 bei $37^{\circ}$ gasbilden-

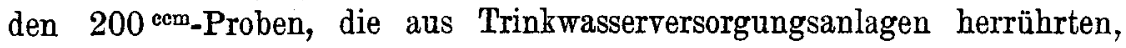
wurde zu gleicher Zeit auch bei $42^{\circ}$ Gasbildung beobachtet bei 21 Proben. Aus den 48 bei $37^{\circ}$ gasbildenden Proben konnten $20 \mathrm{mal}$, d. h. in 43.8 Prozent der Fälle, aus den 21 bei $42^{\circ}$ dextrosevergärenden Proben $11 \mathrm{mal}$, d. h. in 52.3 Prozent der Fälle, Colibazillen gefunden werden. 2 mal ließen sich allein bei $42^{\circ}$ Colibazillen nachweisen.

57 in gleicher Weise vergleichend ausgeführte Elbwasseruntersuchungen hatten folgendes Ergebnis: Colibazillen wurden $18 \mathrm{mal}$ allein bei $37^{\circ}$, 13 mal allein bei $42^{\circ}$ Bebrütung und 26 mal übertinstimmend bei beiden Methoden gefunden. Bei $37^{\circ}$ wurde $16 \mathrm{mal}$, bei $42^{\circ} 17 \mathrm{mal}$ Gasbildung gesehen ohne nachherigen Colibefund. Ein wesentlicher Vorteil der Bebrūtung bei $42^{\circ}$ vor der $37^{\circ}$ Bebrütung ergab sich somit nicht.

Zur weiteren Untersuchung der in Dextrosebouillon angereicherten Proben bewährten sich die Nährböden von $\nabla$. Drigalski-Conradi (59), von Endo (60) und von Guth (61). ${ }^{1}$ Besonders der Endosche Fuchsinagar erwies sich bei Bearbeitung größeren Materials als wertroll. Bei seiner Herstellung ist zu beachten, daB eine nicht zu geringe F'uchsinmenge hinzugesetzt wird. Zu einem Liter Agar geben wir $10^{\mathrm{eem}}$ einer 24 stündigen Fuchsinalkohollösung (15 grm Fuchsin $+100^{\mathrm{ccm}} 96$ prozent.

1 Der Guthsche Alizarinmilchzuckeragar, bzw. Alizarinmilchzuckermalachitgrünagar zeichnet sich durch die scharfe Differenzierung der säure- und alkalibildenden Kolonien, durch gate Haltbarkeit und Billigkeit ans. Die säurebildenden Kolonien, auch wenn sie ziemlich dicht stehen, beeinflussen die anderen verhältnismäBig wenig. Bacterium coli färbt den Nährboden gelb und hellt ihn zugleich auf; Typhusbazillen z. B., die graublaue Kolonien bilden, lassen ihn undurchsichtig. 
Alkohols) und reduzieren mit $25^{\mathrm{ccm}} 10$ prozentiger Natriumsulfitlösung (Natriumsulfitkristalle $10^{\mathrm{grm}}+100^{\mathrm{cm}}$ Wasser.) Eine von Klinger (62) vorgeschlagene Fuchsinmenge von $5^{\mathrm{ccm}}$ einer 10 prozentigen Lösung genïgte nicht immer. Es ist möglich, daB eine neu bezogene Fuchsinprobe eine geringere Lösungsfähigkeit aufwies. Auf dem Endonährboden sind die Colikolonien wegen ihres Fuchsinglanzes leicht zu erkennen. Hinzu kommt das flache, feste Wachstum der Kolonien, die von einem roten Hof umgeben sind. Auch andere Bakterien zeigen auf Endoplatten den schillernden Glanz der Colikolonien.

Auf die Identifizierungsmethoden der von der Platte gewonnenen Reinkulturen gehe ich im einzelnen nicht ein. Es sei erwähnt, daß der Hauptwert der Gelatineröhrchen in der Feststellung der Nichtverflüssigung liegt. Um die seltenen Fặlle, in denen eine langsame, erst nach mehr als 2 Tagen zu beobachtende Verflüssigung der Gelatine stattfindet, nicht zu übersehen, kann es sich empfehlen, einem modifizierten Vorschlage von Rivas (63) zu folgen. Die beimpften Gelatineröhrchen werden zur Beschleunigung des Wachstums 2 Tage bei $\mathbf{3 7 ^ { \circ }}$ bebrütet und dann zur Feststellung der Verflüssigung in Eiswasser gesetzt.

Rivas (63) hatte 3 für Colibazillen angeblich charakteristische Reaktionen mitgeteilt, die mit einer 48 stündigen Dextrosebouillon angestellt wurden. Es sollten durch Zugabe von gewissen Mengen von Natronlauge bzw. Natronlauge und Sehwefelsăure bestimmte Farbenerscheinungen auftreten, bzw. durch Zusatz Fehlingscher Lösung in bequemer Weise ein Zuckergehalt festgestellt werden können. Ich habe die Reaktionen an einer Reihe von nachweislichen Colikulturen nachgeprüft, konnte aber die Rivasschen Angaben nicht bestätigen.

Schließlich sind noch zwei neuere Verfahren kurz zu besprechen, die unter Verzicht auf eine Anreicherung die Anwesenheit von Colibazillen unmittelbar zu bestimmen suchen. Gage (64) schlug in der Absicht, die gewöhnliche Keimzählmethode qualitativer zu gestalten, vor, neben den Gelatineplatten auch Lackmuslaktoseagarplatten anzusetzen, die bei $30^{\circ}$ und bei $40^{\circ}$ bebrütet werden. Eine Zählung nach 16 bis 20 Stunden sollte bereits AufschluB geben über die Anwesenheit also besonders ron Colibazillen. Die Methode ist auch hier einer Nachprüfung unterzogen. Es zeigte sich jedoch, daß nach der erwähnten Zeit meist nur ein recht spärliches Wachstum vorhanden war. Ein praktischer Wert konnte dem Verfahren nicht beigelegt werden.

Bei der anderen Methode, die zuerst von Ingelfinger (65) und Marmann (66) mitgeteilt, dann von Marmann (21) ausführlich beschrieben wurde, werden zwecks quantitativen Nachweises der Colibazillen 5 bis $10^{\mathrm{ccm}}$ des zu untersuchenden Wassers auf einer Endoplatte unter künst- 
lichem Luftzug rasch zur Verdunstung gebracht. Die Bebrütung der Platte erfolgt bei $41^{\circ}$. Eine vergleichende Untersuchung mit anderen Verfahren erzielte keine schlechteren Resultate. Kaltblütercoli lommen angeblich nicht zur Entwicklung. Jedenfalls verdient das Verdunstungsverfahren weitere Nachprüfung. Anderweitige Erfahrungen liegen bisher nicht vor.

Die bisher zum Nachweis von Colibazillen vurgeschlagenen Methoden, insbesondere die Anreicherungsflüssigkeiten, gestatten das Auffinden der Colibakterien nur in einem gewissen Prozentsatz. Als besonders geeignet empfiehlt sich die Anreicherung in 1 prozentiger Dextrosebouillon bei $37^{\circ}$.

Der Colibacillus ist ein regelmäßiger Bewohner des menschlichen Darmes und scheint, wie die Hühnchenversuche von Schottelius (67) anzeigen, einen für die Verdauung wesentlichen Faktor darzustellen. Er ist weiterhin im Darminhalt zahlreicher Warmblüter festgestellt worden. Wie aus den Arbeiten von Dyar und Keith (68), Fremlin (69), Smith (2), Brotzu (70), Kern (71), Belitzer (72), Hoag (73), Houston (74), Moore und Wright (75), Eyre (76), Ferreira, Horta und Paredes (77) u. a. hervorgeht, sind Colibazillen nachgewiesen worden bei Pferden, Rindern, Ziegen, Schafen, Schweinen, Hunden, Katzen, Hasen, Kaninchen, Meerschweinchen, Ratten, Mäusen, zahlreichen Raubtieren, Tauben, Hühnern, Truthühnern, Möven, Sperlingen, einigen Wasserrögeln, Enten, Raubrögeln. Ferreira, Horta und Paredes, welche bei 46 Tierarten (8 Vögeln und 38 Säugetieren) ungefähr in 93 Prozent aus dem Stuhl der verschiedenen Tiere Colibazillen züchteten, stellten fest, daB sich die aus den verschiedenen Tierarten isolierten Colibazillen nicht unterscheiden. Es bestehen keine Differenzen $\mathrm{zwischen}$ den Colibazillen der Pflanzenfresser, Fleischfresser und Vögel.

Von Untersuchungen, die sich mit dem Nachweise von Colibazillen aus Kaltblütern beschäftigen, erwähne ich hier folgendes: Eyre (76) untersuchte eine Reihe von Seefischen, die 2 Meilen vom Lande in einer Tiefe ton etwa $8^{\mathrm{m}}$ gefangen waren. Aus aseptisch entnommenen Proben vom Darminhalt konnte er Colibazillen nachweisen in sämtlichen untersuchten Fischarten (Sprotten, Zungen, Schollen, Hundshai, Engelfisch, Roche, Stint, Barbe, Kliesche, Petersfisch).

Houston (74) untersuchte 38 Fische und Seekrebse, deren Herkunft nach Xöglichkeit den Verdacht einer Verunreinigung ausschloB, und fand 
bei fünf Tieren (Merlan, Krabbe, Einsiedlerkrebs, Steinbutt, Scholle) typische Colibazillen. Er ist der Ansicht, daB selbst coliähnliche Mikrobien unter natürlichen Verhältnissen, d. h. bei AusschluB von Abwasserverunreinigung, im Fischdarm nicht vorhanden sind.

Johnson (78) fand $47 \mathrm{mal}$ Colibazillen im Magen von 67 Flußfischen. Bei Fischen, die aus nicht verunreinigtem Wasser stammten, gelang der Nachweis seltener. Desgleichen erhielten Hoag (73) und Chick (12) bei Fischuntersuchungen positive Resultate. Amyot (79) dagegen hat bei Untersuchung von 23 Fischen in keinem Falle Colibazillen gefunden.

Vor einer Reihe von. Jahren hat Prof. Kister (80) am hiesigen Institut Untersuchungen angestellt. Aus 21 Fischkotproben gelang es zweimal, aus einem Frosehkot einmal Colibazillen nachzuweisen. Bei einer weiteren Untersuchung fanden sich Colibazillen im Darminhalt einer Scholle, während 10 Schollen, 4 Stinte, 3 Sturte, 1 Schlei negatives Ergebnis hatten. Zur Erklärung dieses verhältnismäBig seltenen Nachweises von Colibazillen sei erwähnt, daB das Untersuchungsmaterial nicht angereichert, sondern direkt auf Drigalskiplatten ausgestrichen worden war.

Von Mallannah (51) Anfang 1906 im hiesigen Institut vorgenommene Untersuchungen von Fischkot erstreckten sich auf 32 Fischproben (6 Goldfische, 3 Hechte, 9 Sture, 7 Schleie, 4 KleinweiBfische, 3 unbenannte Fische). Von den isolierten coliähnlichen Stäbchen bildeten alle bei $23^{\circ}$ und $37^{\circ} \mathrm{Gas}$, dagegen nie bei $46^{\circ}$. $12 \mathrm{mal}$ lieBen sich Colibazillen finden, d. h. in 37.5 Prozent der Untersuchungen.

Bei eigen en Fischversuchen verfuhr ich so, daB die nach Möglichkeít aseptisch entnommenen Darmeingeweide bei $37^{\circ}$ in Glukosebouillon bebrütet und von hier am folgenden Tage weiter verarbeitet wurden. Aus 17 Fischdärmen (je 2 Goldfische, Butte, je 4 Bitterlinge, Sture, 5 Stinte) gelang der Colinachweis $7 \mathrm{mal}=41$ Prozent (Stur, je 2 mal Butt, Goldfisch und Bitterling). AuBerdem ließen sich bei einem colipositiven Stur ebenfalls aus der Leber Colibazillen züchten, während 11 andere Fischlebern ein colinegatives Ergebnis hatten.

Bei späteren Versuchen gelang es mit Hilfe der Anreicherung bei 16 Fischen (7 Stinte, 5 Sture, 4 Schollen) $11 \mathrm{mal}=68 \cdot 75$ Prozent Coli im Darminhalt nachzuweisen. Es fehlen mir allerdings Anhaltspunkte über den Reinheitsgrad des Wassers, aus dem die untersuchten Fische stammten.

Aus Froschdarm isolierte Thomann (47) Colibazillen, die bei $46^{\circ}$ keine Gasbildung zeigten. Moore und Wright (81) fanden sie nicht im Froschdarm.

Ein besonderes Interesse beanspruchen ferner Colibefunde in Austern. Kister (80) isolierte aus 60 Austern nur 4 mal Colibazillen. Dagegen fand 
Soper (82) in 60 Prozent der untersuchten Austern Colibazillen, doch auch das umgebende Wasser enthielt sie. Ayers (83) stellte unter 294 Austern 11 mal in die Coligruppe gehörige Bakterienarten fest. Die Häufigkeit der in Austern gefundenen Colibazillen wird naturgemäB sehr abhängig sein von dem Reinheitsgrade des Wassers, in dem sich die Austern vor der Untersuchung befunden haben. So fand Houston (84) viel weniger Colibazillen in Austern, die aus reinem, als aus verunreinigtem Wasser stammten. Nach Klein (85) enthält die normale Auster keine Colibazillen. Derselben Ansicht ist Fuller (86). Browne (87) hält Austern, die in 1 com Schaleninhalt Colibazillen enthalten, zum GenuB für bedenklich, weil damit angezeigt würde, daß das Wasser, aus dem sie herrührten, verunreinigt war.

Auch eine einwandfreie Entnahme der Tntersuchungsprobe bietet gewisse Schwierigkeiten. Schwarz (88) bohrte daher die zuvor desinfizierten Austern mit sterilem Bohrer an und pipettierte durch die so erhaltene Offnung den Schaleninhalt zur Untersuchung aus. Auf diese Weise vermochte Schwarz, soweit die bisherigen Untersuchungsergebnisse, die mir freundlicherweise zur Verfügung gestellt sind, vorliegen, von 57 Austern bei Untersuchung von $0.1^{\mathrm{cem}}$ Saft $1 \mathrm{mal}=1.8$ Prozent, von 13 Austern bei Ansetzen von 1.0 cem $2 \mathrm{mal}=15.4$ Prozent Colibazillen zu züchten. $\mathrm{DaB}$ die Art der Untersuchung das Coliergebnis wesentlich beeinfluBt, zeigte sich z. B. daran, daB 10 gleichzeitig untersuchte Austern mit der früheren Methode $7 \mathrm{mal}$, mit der Bohrmethode 2 mal ein colipositives Ergebnis lieferten.

Bettencourt und Borges (89) untersuchten den aseptisch entnommenen Darminhalt von 17 verschiedenen, zu den niederen Vertebraten gehörenden Tieren (Frösche, Salamander, Molche), indem sie von einer Aufschwemmung direkt auf Endoplatten impften. Auf diese Weise fanden sie in zwei Fällen (Anguille und Serpent d'eau) typische Colibazillen, d. h. in ungefähr 12 Prozent der Zahl der untersuchten Tiere. Sie halten das Vorkommen von Bacillus coli im Darm der niederen Vertebraten für einen zufälligen Befund.

Weitere eigene Untersuchungen erstreckten sich auf die Feststellung, ob der Flohkrebs (Gammarus pulex) Colibacillen beherbergt. Diese Frage hat eine praktische Bedeutung, z. B. bei Filteranlagen, deren Reinwasserbehälter von Flohkrebsen heimgesucht werden. Es fragt sich, ob Colibazillen und schlieBlich dann auch pathogene Bakterien durch Gammarus pulex verschleppt werden.

Es sind im ganzen 102 Flohkrebse untersucht worden, und zwar wurde der in sterilem, später in 1 prozent. Karbolwasser abgespülte Krebs, um den Darm unberührt mit der AuBenfläche des Tieres entnehmen zu 
können, an den Körperenden mit sterilen Pinzetten gefaßt und auseinandergezogen. Nach Trennung der äuBeren Hülle blieb als einzige Verbindung das Darmrohr bestehen, das sich mit einer dritten Pinzette dann fassen lieB. Der Darm wurde in Gärungsröhrchen bei $37^{\circ}$ bebrütet.

Von den 102 Flohkrebsdärmen wurden in einer Probe Bacterium coli gefunden.

Als Kontrolle waren 16 Körperteilproben und 12 ,Spülwasserproben“ auf Colibazillen untersucht, indes mit negativem Ergebnis.

Es zeigte sich also, daB Colibazillen wohl nur ganz ausnahmsweise im Darm von Gammarus pulex gefunden werden.

Die Untersuchung von 6 Asseln (Asellus aquaticus) auf Colibazillen, wie ich anschlieBend erwähne, verlief ebenfalls negativ.

Die Colibazillen der Kaltblüter haben ja neuerdings ein besonderes Interesse gewonnen, nachdem behauptet worden ist, daB die Eijkmansche Methode gestatte, sonst biologisch und morphologiseh übereinstimmende Colibazillen in sogenannte Warmblüter- und Kaltblütercolibazillen zu trennen, je nach ihrem Gärvermögen bei einer Temperatur von $46^{\circ}$ [Christian (45), Thomann (47), Hilgermann (57)]. Da jedoch auch bei Kaltblütern bei $46^{\circ}$ Dextrose vergärende Colibazillen vorkommen (s. S.269 unten), so läßt sich auf Grund der bisherigen bei Kaltblütern erhobenen Colibefunde nicht entscheiden, ob das Gärvermögen bei $46^{\circ}$ in der Tat eine Eigentümlichkeit der Warmblütercolibazillen ist. Immerhin könnte gesagt werden, da $B$ jene, aus Kaltblütern stammenden, bei $46^{\circ}$ Gas bildenden Colibazillen keine eigentlichen Kaltblütercoli, sondern ursprünglich Warmblütercoli wären, die mit der Nahrung in den Kaltblüterdarm eingeführt wurden. Das im einzelnen Falle za entscheiden, dürfte unmöglich sein. Man könnte dann auch andererseits an die Möglichkeit denken, daß ursprünglich aus Warmblütern stammende Colibazillen sich mit Verlust der Gärfähigkeit bei $46^{\circ}$ an den Kaltblüterorganismus gewöhnt hätten. Ein solcher Colibacillus müBte dann für die Beurteilung des Wassers dieselbe Bedeutung haben wie ein Warmblütercoli. Ich meine, daB der Begriff Warmblüter- bzw. Kaltblütercoli noch zu sehr der tatsächlichen Unterlagen entbehrt, als daß daraus praktische Konsequenzen gezogen werden sollten. Für die praktische Beurteilung eines Trinkwassers kann es auBerdem im allgemeinen auch nicht gleichgültig sein, ob in ihm Kaltblütercoli gefunden werden. Unter denselben Voraussetzungen würde ebenso ein Kaltblütercolibefund als Indikator einer unerwünschten Beimengung zum Wasser bezeichnet werden müssen, als wenn es sich um Warmblütercoli handelte. In guten Brunnenwässern werden unter bestimmten Voraussetzungen auch keine Kaltblütercoli nachgewiesen. 
Das bisher über das Vorkommen der Colibazillen Mitgeteilte läßt sich kurz folgendermaßen zusammenfassen: Der Colibacillus wird nahezu regelmäBig im Warmblüterdarm gefunden. Aus dem Kaltblüterdarm gelingt der Nachweis nicht mit derselben RegelmäBigkeit, jedoch in einer groBen Zahl der Fälle. Einer je niedrigeren Klasse das untersuchte Tier angehört, um so seltener finden sich Colibazillen.

Ich möchte weiterhin über Untersuchungen berichten, die sich auf die Verbreitung der Colibazillen in der Außenwelt (auBerhalb des tierischen Darms) erstrecken. Gilt der tierische Darm allein für die Ausgangsstelle der Colibazillen, so muB erwiesen werden, daB ihr Vorkommen auBerhalb des tierischen Darms als zufälliger Befund anzusehen ist. Es gibt in der Literatur eine Reihe von Mitteilungen, die widersprechend sind, die aber unter dem Gesichtspunkt, da $B$ Versprengung fäkalen Materials nur zu oft stattfindet, vielleicht doch einheitlicher beurteilt werden können. Es müBte festgestellt werden, daB Colibakterien nur dort aufzufinden sind, wo Fäces hingelangen oder hingelangt sind.

Verschiedene Autoren haben ihr Augenmerk besonders auf den Nachweis von Colibazillen auf Pflanzen und Pflanzenprodukten, die der mensehlichen Nahrung dienen, gerichtet. Klein und Houston (90) stellten unter 12 Sorten ausländischen Korns, das in einem Londoner Magazin gekauft war, 2 mal Colibazillen fest. Dagegen fanden sich in der Mehrzahl ihrer Proben Bakterien, die den Colibazillen mehr oder weniger nahestanden. In 6 Mehlproben, die aus einem Laden der Stadt herrührten, lieBen sich verhäitnismäBig große Mengen Colibazillen nachweisen. Sie halten den typischen Colibacillus nicht für einen gewöhnlichen Bewohner der Kornfrüchte.

Clark und Gage (26) fanden auf Zerealien, die sorgfältig auf Feldern gesammelt waren, nie Coli. Der Nachweis von Colibazillen in Proben, die aus Magazinen herrührten, halten sie für zufällige Befunde. Winslow und Walker (91) untersuchten 178 Kornproben und 40 Gräserproben auf Colibazillen mit negativem Ergebnis. Weiterhin seien die Untersuchungen von Bettencourt und Borges (89) erwähnt. Von 35 verschiedenen Zerealien und Gemüsen, die zum Teil aus einem Krämerladén, zum Teil aus einem Engrosgeschäft bezogen waren, ergaben $8=$ 21.6 Prozent (Gerste, Erbse, Mais, Hirse, „Korn“, Hafer) einen colipositiven Befund. Von den colipositiven Proben stammte eine (Erbse) aus dem Krämerladen, die übrigen aus dem Engrosgeschäft. Wenn man berücksichtigt, wie häufig die erwähnten Materialien bis zum Augenblicke des Verkaufs mit Colibazillen infiziert werden konnten, so sei es auf- 
fallend, meinen die Verfasser, daß nicht häufiger Colibazillen gefunden werden. In 2 Proben "Abfall" fanden sie beidemal Colibazillen. Auch Bettencourt und Borges halten die Anwesenheit der Colibazillen für einen rein zufälligen Befund, der keineswegs einen SchluB auf ihre Ubiquität zulasse.

Bei Untersuchungen über fäkale Verunreinigungen auf Obst und Gemüse fand Ressel (92) den Colikeim zwar weit verbreitet, jedoch nicht auf reinen Sorten. Er sieht das Vorkommen der Colibakterien in der Außenwelt für ein Zeichen vorangegangener fäkaler Verunreinigung an.

Im Gegensatz zu diesen, einer Ubiquität der Colibazillen abgeneigten Urteilen, sprechen sich eine Reihe von Autoren dahin aus, daB der Colibacillus nicht als ein zufälliger Befund auf Zerealien usw. anzunehmen sei. So stellt Prescott (93) zum Teil in Gemeinschaft mit Smith, Mixter und Gunn (94) unter 47 verschiedenen Milchzuckervergärern, die hauptsächlich aus Zerealien und Müllereiprodukten (Mehl, Kleie, Hafer, Gerste, Korn) herrührten, 25 Stämme fest, die typische Colireaktionen gaben. Prescott hält es nicht für wahrscheinlich, daB einige dieser Organismen intestinalen Ursprungs waren. Gordan (95) fand Colibazillen in Kleie und zwar regelmäBig in 0.1 und $0.01 \mathrm{grm}$ Kleie schlechter Qualität; Düggeli (96) wies in gesunden Samen- und Keimpflänzchen einige Male Colibazillen nach. Näheres über die Untersuchungsmethoden dieser Autoren und über ihre Begriffsbestimmung des Bacterium coli ist nicht mitgeteilt. Dasselbe gilt von den Untersuchungen Barthels (97), nach dessen Ansicht Colibazillen sich sowohl auf allen kultivierten und wilden Pflanzen, ebenso wie in der Erde vorfinden.

Mehrfach erwähnt finden sich in der Literatur die Untersuchungen ron Papasotiriu (98) über das Vorkommen des Bacterium coli commune in Teig, Mehl und Getreide. Im Auftrage von Prof. Lehmann unter Fortsetzung von Arbeiten von Wolffin, Flörsheim und F. Fränkel untersuchte Papasotiriu 4 Proben von Schwarzbrot- und WeiBbrotteigen verschiedener Bäckereien auf Colibazillen, indem er 1 Ose Teig in $10^{\mathrm{cem}}$ Zuckerbouillon anreicherte. Die Colidiagnose stützte sich auf das Verhalten der Mikroorganismen auf Kreidezuckeragar, in Zuckeragar, auf Prüfung auf Indolbildung, Milchkoagulation, Eigenbewegung, typisches Aussehen auf ,allen" Nährböden. Papasotiriu fand stets massenhaft Colibazillen, wenig andere Keime. Ein ebenfalls positives Ergebnis hatte die Untersuchung von 4 Weizenmehlproben. Eine mehrfache Prüfung verschiedener Zerealien und Gemüse (Weizenkörner, Roggen, Gerste, Hafer, Erbsen, Bohnen, Mais) fiel auch fast durchweg positiv aus; bei diesen Untersuchungen wurden je etwa 10 Körner in ungemahlenem 
Zustande in $10^{\mathrm{cm}}$ Zuckerbouillon gebracht. Infolgedessen sieht Papasotiriu das Bacterium coli als den Organismus der Sauerteiggärung des Brotes an und hält ihn als Indikator für Wasserverunreinigung von geringem Werte. Trotz der Häufigkeit seiner Colibefunde redet Pa pasotiriu einer eventuell quantitativen Verwertung des Colititers das Wort.

Von den zuletzt aufgeführten Arbeiten sind die Mitteilungen Papasotirius besonders geeignet, die Ansicht von der Ubiquität der Colibazillen zu unterstützen. Es sei mir hier gestattet, die Ergebnisse einiger Versuche folgen zu lassen, die zum Teil eine Nachprüfung der erwähnten Untersuchungen darstellen.

24 Proben von 4 verschiedenen Mehlsorten (Roggen, Weizen, Hafer, Mais), die aus 6 versehiedenen Geschäften bezogen waren, wurden auf Anwesenheit von Colibazillen untersucht. Soviel Mehl, wie auf einer Normalöse gehäuft sich hält, wurde je in 2 Gärungskölbchen gebracht, von denen das eine bei $37^{\circ}$, das andere bei $46^{\circ}$ bebrütet wurde. In keinem Falle gelang es Colibazillen zu züchten. Bei $37^{\circ}$ bildeten 10 Proben (Hafermehl $1 \mathrm{mal}$, Weizenmehl $3 \mathrm{mal}$, Roggenmehl $6 \mathrm{mal}$ ), bei $46^{\circ} 9$ Proben (Hafermehl $1 \mathrm{mal}$, Weizenmehl $2 \mathrm{mal}$, Roggenmehl $6 \mathrm{mal}$ ) Gas. Bei $37^{\circ}$ blieben eine Hafermehlprobe, bei $46^{\circ}$ je 3 Weizenmehl- und Hafermehlproben steril. Auf den Endoplatten, die mit Material aus den Gasbildung anzeigenden Röhrchen beschickt waren, wuchsen zumeist Alkalibildner.

Demnach wird unter den hiesigen Verbältnissen in Mehlproben, die selbst aus kleineren Verkaufsläden bezogen sind, in der Regel der Colibacillus nicht gefunden; man kann also nicht sagen, daß der Colibacillus als ein dem Korn von Natur anhaftender Parasit aufzufassen ist.

Einige weitere Arbeiten befassen sich mit der Verbreitung der Colikazillen in der AuBenwelt. Als Ausgangspunkt der Verschleppung sind naturgemä $B$ die Fäkalien anzusehen. Es ist daher von Interesse, festzustellen, wieweit bei der Defäkation ein Verspritzen colihaltigen Materials erfolgt. Neumann (46) untersuchte mittels der Eijkmanschen Anreicherung, der eine Identifizierung folgte, 27 Sitzbretter zumeist „öffentlicher" Klosetts Berlins und fand nur 7 colifrei; von 4 untersuchten Abortdeckeln erwies sich nur einer als frei von Colibazillen. Von 15 eisernen Griffen der Spülvorrichtung gelang es bei 6, von 15 Messinggriffen in keinem Falle, von einem Porzellangriff in einem, Colibazillen nachzuweisen. In 10 Treppengeländerabstrichen fand Neumann einmal Colibazillen. Neumann ist der Ansicht, daB überall dort, wo die menschliche Hand hingelangt, Colibazillen $z u$ finden sind, abgesehen $d a$, wo die Keime rasch zugrunde gehen.

Ähnliche Untersuchungen liegen in einer ausführlichen Dissertation von Sonnen (99) vor, die sich mit der Verbreitung von Schmutzstoffen 
in Amsterdam befaBt. Es sind 139 Klosetts in der Weise untersucht, daB von Stellen, die am ehesten eine Verschmutzung vermuten lieBen, mit bouillongetränkten Wattebäuschen Abstriche vorgenommen wurden. Zur Diagnosestellung wurden die üblichen Reaktionen herangezogen, vor allem aber auch das Gasbildungsvermögen bei $46^{\circ}$. Die Ergebnisse der ausgedehnten Versuche sind kurz folgende: Es erwiesen sich als coliinfiziert:

$$
\begin{aligned}
\text { von } 141 \text { Türknöpfen } \quad 21 & =14.9 \text { Prozent } \\
" \quad 140 \text { Sitzen } & 67=47.9 \quad " \\
" \quad 98 \text { Deckelknöpfen } 37 & =37.8 \quad " \\
, \quad 42 \text { Handgriffen } \quad 6 & =14 \cdot 3 \quad "
\end{aligned}
$$

Die Verteilung der Fundstätten ergab eine Klassifizierung, aus der folgendes mitgeteilt sei: Es fielen colipositiv aus von

$$
\begin{array}{ll}
158 \text { offentlichen Klosetts } & 42=26.6 \text { Prozent } \\
177 \text { Schulklosetts } & 76=42.9 ", \\
165 \text { Klosetts mit Wasserspülung } & 35=21 \cdot 2 " \\
258 \text { Klosetts ohne Wasserspülung } & 97=37.6 "
\end{array}
$$

Von Wichtigkeit ist es, zu wissen, wie lange sich die Colibazillen, die mit Fäkalstoffen in die AuBenwelt gelangen, lebend erhalten. Neumann rermochte noch am 5. Tage Colibazillen aus einer $1^{\mathrm{cm}}$ dicken Fäcesschicht, die auf steriles Holz gestrichen war, zu isolieren. Sonnen stellte fest, daB die Colibazillen auf Porzellan nach 2 Tagen, auf Eisen nach 6 Stunden, auf Rohholz nach 10 Stunden, auf gefärbtem oder poliertem Holz nach 1 Tag, auf Kupfer anscheinend sofort vernichtet werden. Er fand Colibazillen auf:

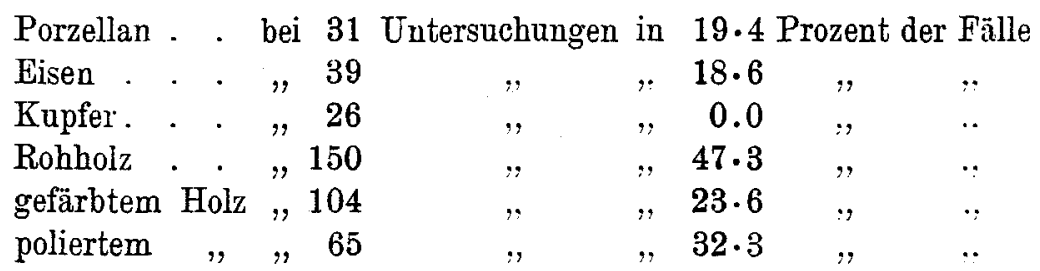

Aus den Sonnenschen Versuchen scheint mir hervorzugehen, daB auf Klosetts in Wirklichkeit eine Verspritzung colihaltigen Materials ungünstigen 'Falls in etwa 50 Prozent der Fälle nachzuweisen ist. Dieser rerhältnismäBig seltene colipositive Befund dürfte zum Teil auf das rasche Absterben der Colibazillen zuräckzuführen sein, die, wie die Versuche zeigen, ein Austrocknen nur kurze Zeit rertragen.

Berghaus (100) gelang es in seinen Versuchen über die Verschleuderung ron Kotteilchen durch den Akt der Defäkation Colibakterien auf 
Agarplatten nachzuweisen, die auf dem Sitzrand und bis zu etwa $75^{\mathrm{cm}}$ ron demselben entfernt aufgestellt waren, und zwar nur dann, wenn es sich um diarrhoischen Stuhl handelte. Eine erheblich gröBere Verschmutzung konnte übrigens konstatiert werden, wenn behufs Entfernung der Kotmassen aus dem Becken die Spülvorrichtung in Tätigkeit gesetzt wurde. Demgegenüber beobachtete Sonnen bei Spülklosetts einen geringeren Colibefund als bei Klosetts ohne Wasserspülung.

In den öffentlichen Pissoirs findet, wie die Versuche von Berghaus mit Prodigiosuskulturen zeigen, a. U. eine weitgehende Verstreuung von Keimen statt. Bei Pissoirbecken ging die Keimverbreitung allerdings nicht über $50 \mathrm{~cm}$ nach der Seite hin. Eine Verstreuung von Colikeimen durch den Urin kommt indes praktisch weniger in Betracht als die durch Fäces.

Uberall dort, wo Fäcespartikel hingelangen, sind auch die Voraussetzungen für den Nachweis von Colibazillen gegeben. Erwähnt sei, daB Pfuhl (101) und Brunner (102) Colibazillen auf den Kleidern von Soldaten, Henke (102 a) auf Verbandstücken, Heubner (103) an den Fingern und Nagelfalzen, Solowjew (104) und Zieleniew (105) im Staub rou Spitalgeräten, Ca cace (106) konstant im Staub von Schulzimmeru fanden.

Ich selbst habe gelegentlich einige Untersuchungen über die Verschleppung von Colikeimen im Hygienischen Institut angestellt. Die zu untersuchenden Stellen wurden mit in Bouillon getränkten Wattebäuschchen abgerieben, die dann in Zuckerbouillon bei $37^{\circ}$ bebrütet wurden. Die Diagnosenstellung erfolgte in der gewohnten Weise. Es kamen zur Untersuchung Klosettsitze (vorderer und hinterer Teil), Griffe der Spülvorrichtung, Türgriffe, Tische, Stühle, Fußboden, Telephonanlagen und andere Stellen, die einer Infizierung besonders ausgesetzt erschienen.

Von 93 Proben fielen $8=8.6$ Prozent colipositir aus, und zwar fanden sich Colibazillen 3 mal von 8 Untersuchungen auf dem vorderen Teil des Klosettsitzes, 1 mal auf dem hölzernen inneren Klosetttürgriff, 1 mal auf dem Fußboden des Laboratoriums, 2 mal auf dem FuBboden eines viel benutzten Aufenthaltsraumes, $1 \mathrm{mal}$ an einem Stuhl, der in diesem Raum stand. Ohne auf die Einzelheiten der Befunde einzugehen, ist es bemerkenswert, wie selten der Nachweis gelang. Selbst wenn 20 Proben von Messinggriffen, auf denen ja anscheinend die Colibazillen alsbald absterben, in Abzug genommen werden, so würde doch nur eine Prozentzahl positiver Befunde von 11.0 herauskommen.

Sind diese eigenen Untersuchuugen vielleicht auch nicht umfangreich genug, jedenfalls liefern ihre Ergebnisse auch einen Beitrag für die Behauptung, daß Colibazillen nicht so häufig in der AuBenwelt und selbst in nächster Umgebung des Menschen gefunden werden, wie angenommen werden sollte. 
Weiterhin sind die Tntersuchungen zu besprechen, die sich im besonderen mit dem Nachweise der Colibazillen im Trinkwasser befassen. Werden Colibazillen in der Tat häufig in zu Trinkzwecken dienenden Wässern gefunden? Von der Beantwortung dieser Frage wird die Brauchbarkeit des Colitestes zur Beurteilung eines Trinkwassers im wesentlichen abhängen.

Zahlreiche Autoren haben zu der Frage, wie der Colibefund im Trinkwasser zu-beurteilen ist, Stellung genommen. Ohne auf den gröBeren Teil der hierher gehörigen Untersuchungen besonders aus älterer Zeit näher einzugehen, seien erwähnt die Arbeiten von Lehmann (107), Miquel (108), Kruse (109), L oeffler (110), Gärtner (111), Burri (112), Abba (113), Refik (114), Poujol (115), Moroni (116), Levy und Bruns (117), WeiBenfeld (118), Papasotiriu (98), Saito (1). Diese Autoren nehmen einen im allgemeinen ablehnenden Standpunkt ein gegenüber der Brauchbarkeit des Colibefundes zur Trinkwasserbeurteilung.

Demgegenüber halten andere Forscher in mehr oder weniger ausgesprochener Weise die Untersuchung des Trinkwassers auf Colibazillen für geeignet, AufschluB über stattgehabte Verunreinigung zu erlangen. Ich führe folgende Namen an. Péré (119), Dunbar (120), Schardinger (121), Guiraud (122), v. Freudenreich (3), Mez (123), Kübler und Neufeld (124), Jordan (125), Clark und Me Gage (126), Houston (127), Chick (12), Pfaundler (128), Meusburger und Rambousek (129), Petruschky und Pusch (130), Hirschbruch und Sehwer (131), Winslow (132), Savage (133), Vincent (133a), Christian (45), Kaiser (11), Seige und Gundlach (134), Venema (135), Thomann (47), Lange (54), Bulir (13), Worthmann (52), Totsuka (16), Ressel (92), Federolf (56), Marmann (21), Hilger$\operatorname{mann}(57)$.

Kaiser (11)-Graz berichtet über die Untersuchungen von 49 Wasserproben aus Schachtbrunnen. Das Wasser dieser Brunnen, die durchschnittlich 8 bis 12 und mehr Meter Tiefe, einen Durchmesser von $1^{\mathrm{m}}$ hatten und meist mit Steinplatten zugedeckt waren, wurde mittels Saugpumpen durch hölzerne, seltener eiserne Röhren zutage gefördert. Kais er bediente sich zum Colinachweise des Heuinfusanreicherungsverfahrens, das er der Pariettischen Methode und der Peptonkochsalzanreicherung besonders weǵen Hemmung verflüssigender Keime vorzieht. Es kam jedesmal 1 Liter des betreffenden Brunnenwassers zur Untersuchung.

Auf Grund der bakteriologischen Ergebnisse teilt Kaiser die Brunnen ein 1. in solche mit dem Befunde von typischem Bacterium coli commune $=22$ Proz. aller Fälle; 2. in solche mit dem Befunde ron anderweitigen Bakterien aus der Coligruppe $=30$ Prozent aller Fälle, unter denen er 
Bakterien versteht, denen eine oder mehrere Eigenschaften des typischen Coli abgehen: als Gasbildung, Milchkoagulation, Indolbildung.

Wie aus den. Tabellen Kaisers hervorgeht, finden sich unter seinen 15 ,atypischen" Colistämmen nicht weniger als 7, die sich mit Ausnahme der Fähigkeit, Indol zu bilden, ganz wie typische Coli rerhalten. Jm späterhin Vergleiche zu ermöglichen, habe ich auch diese nichtindolbildenden Stämme zur Gruppe der typischen Colibazillen gerechnet, während Stämme, die Milch nicht koagulierten oder Neutralrot nicht reduzierten, als Colibazillen nicht in Frage kamen. Unter Zugrundelegung dieser Einteilung lieferten von 49 verschiedenen Brunnen bei Untersuchung von 1 Liter 17, d. h. 34.7 Prozent, einen colipositiven Befund. Nach Kaisers Rubrizierung finde ich 11 Brunnenproben mit über 200 Keimen im Knbikzentimeter, von denen $7=$ etwa 64 Prozent Colibazillen enthielten. Von 12 Brunnenproben, die Keimzahlen zwisehen 50 und 200 pro Kubikzentimeter aufwiesen, wurden in $6=50$ Prozent Colibazillen gefunden. Und schlieBlich konnten in 26 Brunnenproben mit einer Keimzahl unter $504 \mathrm{mal}=$ etwa 15 Prozent Colibazillen festgestellt werden. Es ergab sich somit, daB bei den keimärmsten Brunnen auch Coli am seltensten zur Beobachtung $\mathrm{kam}$.

Ein analoges Resultat ergab die Zusammenstellung der Brunnen nach ihrer durch die Lokalinspektion festgestellten Beschaffenheit. Kaiser fand typisches Coli bei einwandfreien Brunnen in 15.3 Proz., bei verdächtigen Brunnen in 33.3 Prozent, wobei bemerkt sei, daB das Attribut „einwandfrei" nur auf Grund einer äuBerlichen Besichtigung der Brunnen erteilt wurde.

Kaiser hält am SchluB seiner Arbeit die Ansicht, das typische Bacterium coli oder die Coliarten seien in Brunnenwässern allgemein verbreitet, für irrig. Eine gewisse Wahrscheinlichkeit spräche zugunsten der Verwertung des Bacterium coli als Indikator für Fäkalverunreinigung.

Während Kaiser in 34.7 Prozent der untersuchten Brunnen Colibazillen fand, teilt Lange (54), der sich bei seinen 70, meist aus Brunnen und Wasserleitungen stammenden Wasserproben der Eijkmanschen Anreicherungsmethode bediente, eine Prozentzahl von 28 mit. Er setzte allerdings nur $10^{\mathrm{com}}$ an. Lange spricht sich gegen die Ubiquität der Colibazillen' aus.

Ein Gegner des Colitestes als Indikator für Fäkalverunreinigung ist Saito (1). Derselbe untersuchte mit Hilfe der 5 prozentigen Milchzuckerbouillon 108 Wasserproben in Mengen von $0.1,0.5,1 \cdot 0,5 \cdot 0,10 \cdot 0$, $100.0^{\mathrm{cem}}$ und $2 \frac{1}{2}$ Litern mit dem Ergebnis, daB in sämtlichen 108 Brunnenwässern Colibazillen gefunden wurden. In Mengen von $0 \cdot 1 \mathrm{cem}$ 
fanden sich in 61 Proz., ron $0.5^{\mathrm{cm}}$ in 88 Proz., von $1 \mathrm{~cm}$ in 92 Proz., von $5.0^{\mathrm{cm}}$ in 96 Prozent, von $10.0^{\mathrm{ccm}}$ in 97 Prozent, von $100^{\mathrm{cem}}$ und $2 \frac{1}{2}$ Litern in 100 Prozent Colibazillen. Zur Identifizierung kam die gebräuchliche diagnostische Methode in Anwendung.

Zur Erläuterung dieses auffallenden Ergebnisses muß aber bemerkt rerden, daB die Keimzahl der untersuchten Proben mit Ausnahme von 4 Fällen über 2000 bis 700000 betrug. Es handelt sich demnach bei diesen in Japan vorgenommenen Untersuchungen im Vergleiche zu biesigen Verhältnissen um außerordentlich keimreiche Wässer, die mit Ausnahme einer Probe keineswegs der Forderang entsprechen, daß ein zu Trinkzwecken geeignetes, selbst filtriertes Wasser im allgemeinen nicht über 100 Keime im Kubikzentimeter enthalten soll. Die Schlußsätze des Verfassers, daB Bacterium coli commune in allen Brunnenwässern nachweisbar wäre, und daB aus der Anwesenheit des Bacterium coli commune in Brunnenwässern nicht ohne weiteres auf eine Verunreinigung des Brunnens mit Fäkalien geschlossen werden könne, dürften daher nicht allgemeingültig und nur so zu verstehen sein, daB der Colinachweis in den untersuchten 108 Proben gerade für eine fäkale Verunreinigung der betreffenden Brunnen spricht.

Im Gegensatz zu Saito bekennt sich Totsuka (16) zu der Ansicht, da $B$ das Vorkommen von Colibazillen im Wasser in irgendwelchen Beziehungen mit fäkaler Verunreinigung steht. Bei den in Greifswald und Umgegend angestellten Versuchen verwandte Totsuka anfangs das Anreicherungsverfahren von Petruschky und Pusch (130), das sich ihm als praktisch brauchbar erwies. Es wurden unter 48 Brunnen 14 als colibazillenhaltig festgestellt $=29.2$ Prozent. Bei diesen Brunnen schwankte der Colititer zwischen 0.1 und $0.0001 \quad(6: 0.1 ; 4: 0.01$; $2: 0.001 ; 2: 0.0001)$. Von 32 Proben mit einer Keimzahl über 200 enthielten $13=40 \cdot 6$ Prozent Colibazillen, unter 14 Proben mit einer Keimzahl von 50 bis 200 wurden $1 \mathrm{mal}=7.1$ Prozent Colibazillen gefunden (2 Proben). Die den höchsten Colititer aufweisenden Brunnenproben enthielten auch die gröBte Keimzahl. 5 der colipositiven Brunnen waren kurz vor der Untersuchung geöffnet gewesen und mit einem Rohr versehen worden.

Weiterhin bediente sich Totsuka als Anreicherungstlüssigkeit der von Loeffler (14 u. 15) angegebenen Milchzucker-Nutrose-Malachitgrünlösung, der sogenannten Grünlösung II oder Paratyphuslösung, die angeblich wegen der Wachstumsbehinderung zahlreicher Wasserbakterien ohne Schädigung der Colibakterien besonders geeignet erschien. Die weitere Prüfung angelegter Agarplattenkulturen erfolgte durch Agglutination mittels eines hochwertigen polyvalenten Coliserums. Auf diese Weise wurden 32 
Brunnen zum Teil öfters untersucht. 4 Brunnen gaben ein colipositives Resultat, und zwar zu wiederholten Malen. Eine daraufhin vorgenommene genauere Lokalinspektion ergab hinreichende Anhaltspunkte dafür, daß colihaltiges Material durch Undichtigkeiten des Bohlenbelages in das Brunnenwasser hineingelangt war.

Eine gröBere Zahl von Trinkwasserproben in Mengen von meist

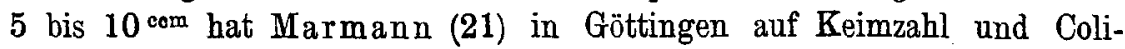
bazillen untersucht. Er bediente sich dabei des in Göttingen üblichen Verdunstangsverfahrens, worüber S. 274 nachzulesen ist. Seine Ergebnisse sind in einer Tabelle mitgeteilt, die jedoch im Text leider keine nāhere Erläuterung gefunden hat. Soviel ich sehe, sind 127 Trinkwasserproben verschiedenster Herkunft untersucht. Nur etwa 37 Prozent erwiesen sich als colihaltig. Die colihaltigen Proben waren in der Regel auch besonders keimhaltige Wässer. Von 37 Kesselbrunnenproben, die ich in der Tabelle zähle, enthielten 20, d. h. etwa 54 Proz., Colibazillen. Die Keimzahl der colipositiven Kesselbrunnenwässer betrug durchsehnittlich 5977, die der colinegativen durchschnittlich 640, auch ein Beweis für den in der Regel zu beobachtenden Parallelismus zwischen hoher Keimzahl und Colibefund. Von 43 colihaltigen Proben fanden sich nur 7, die weniger als 200 Keime enthielten, daron nur 1 mit einer Keimzahl unter 100 .

$\mathrm{Zu}$ einem gleichen Urteil wie Marmann, nämlich daß sich der Colibacillus durchaus nicht in allen Wässern findet, gelangt Hilger mann (57), obgleich dieser Autor Wassermengen von 100.0 und $300.0 \mathrm{~cm}$ untersuchte. Hilgermann fand bei seinen nach der Eijkmanschen Methode ausgeführten über 100 Versuchen $52 \mathrm{mal}$ Colibazillen, die er nach ihrem Gärvermögen bei $46^{\circ}$ in 2 Gruppen einteilt; 38 Stämme, die Gärung bei $46^{\circ}$ gaben, 14, die Traubenzucker bei dieser Temperatur nieht vergärten. Hilgermann konnte feststellen, daB die Stämme der ersten Gruppe aus Wasserentnahmestellen stammten, die auf Grund ihrer örtlichen Lage des bakteriologischen und chemischen Befundes als nicht einwandfrei anzusehen waren; die der anderen Gruppe dagegen stammten aus der Anreicherungsflüssigkeit völlig einwandfreien Wassers. Hilgermann hält diese 14 Stämme der letzten Gruppe für Kaltblütercolibazillen, deren Vorhandensein für die Beurteilung der Güte eines Wassers ohne jede Bedeutun'́g sei.

Es ist meiner Ansicht nach bedenklich, diese Hilgermannsche SchluBfolgerung zu verallgemeinern. Ich halte, wie gesagt, auch die sogenannten Kaltblütereolibazillen, d. h. Colibazillen, die bei $46^{\circ}$ Dextrose nicht rergären, für ein Zeichen einer unerwünschten Beimengung zum Trinkwasser. Unter bestimmten Voraussetzungen darf ein gutes Trink- 
wasser überbaupt keine Colibazillen enthalten. Daß diese Forderung auch praktisch durchführbar ist, beweist die grobe Zahl der Untersuchungsergebnisse von gänzlich colifreiem Wasser.

Jedenfalls geht aus der Arbeit Hilgermanns deutlich hervor, daB gröBere Mengen reinen Wassers - selbst bei Anreicherung von $300 \mathrm{~cm}$ Wasser - frei ron Colibazillen, ja frei ron Bakterien befunden werden. In wirklich reinen Wässern werden Colibazillen nicht gefunden.

Anschließend an diese Mitteilungen lasse ich einige Untersuchungen folgen, die die Häufigkeit der Colibazillen im Trinkwasser demonstrieren sollen, soweit hiesige Verhältnisse in Frage kommen. In einem (mit Grundwasser vermischten) filtrierten Oberflächenwasser, dessen Keimzahl im Jahresdurchschnitt 34.8 betrug, stellten sich die Colibefunde in den verschiedenen Mengen folgendermaßen: Es wurden Colibazillen gefunden

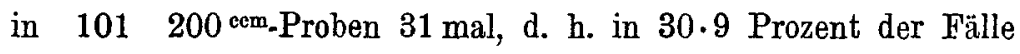

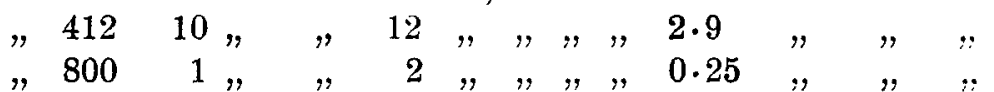

120 Untersuchungen beziehen sich auf weitere Trinkwasserproben. Diese Proben stammten aus Röhren- und Kesselbrunnen der Umgebung Hamburgs und wurden stets am Tage der Entnahme angesetzt auf Keimzahl und Nachweis von Colibazillen in einer Menge von $10 \mathrm{~cm}$.

19 dieser 120 Proben enthielten Colibazillen, d. h. 15.8 Prozent, und zwar verteilen sich 5 positive Colibefunde auf 75 Proben aus Röhrenbrunnen $=6.7$ Prozent und 14 positive Colibefunde auf 45 Proben aus Kesselbrunnen = 31.1 Prozent.

Das Verbältnis der Colibefunde zu den Keimzahlen geht aus folgender Zusammenstellung hervor:

\begin{tabular}{|c|c|c|c|c|c|c|c|c|c|}
\hline \multirow[b]{2}{*}{$\mathrm{K} \in \mathrm{imzabl}$} & \multicolumn{3}{|c|}{ Röhrenbrungen } & \multicolumn{3}{|c|}{ Kesselbrannen } & \multicolumn{3}{|c|}{$\mathrm{Zusammen}$} \\
\hline & 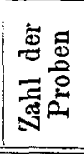 & 总 & 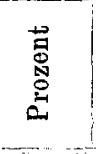 & 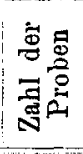 & 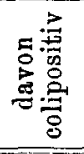 & 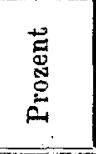 & 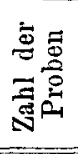 & 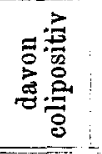 & 惑 \\
\hline über $200 .$. & 12 & 5 & $41 \cdot 7$ & 23 & 9 & 39.1 & 35 & 14 & $40 \cdot 0$ \\
\hline$z$ wischen 200 u. 50 & 6 & 0 & 0 & 13 & 3 & $23 \cdot 1$ & 19 & 3 & $15 \cdot 8$ \\
\hline unter $50 \ldots$ & 57 & 0 & 0 & 9 & 2 & $22 \cdot 2$ & 66 & 2 & $3 \cdot 0$ \\
\hline Zusammen & 75 & 5 & $6 \cdot 7$ & 45 & 14 & $31 \cdot 1$ & 120 & 19 & $15 \cdot 8$ \\
\hline
\end{tabular}

Die Keimzahl der colipositiven Röhrenbrunnenproben schwankte zwischen 220 und 165000 und betrug durchschnittlich 33836 , die der colinegativen schwankte zwischen 0 und 5400 bei einem Durchschnitt von etwa 151. 
Die Keimzahl der colipositiven Kesselbrunnenproben bewegte sich zwischen 2 und 166400 und betrug durchschnittlich etwa 8306 .

Der durchschnittliche Keimgehalt des Kesselbrunnenwassers übersteigt mithin den eines Röhrenbrunnens, wie zu erwarten war, um ein Beträchtliches. Es ist auch nicht zu verwundern, daB Colibazillen in Kesselbrunnen (31.1 Prozent) häufiger gefunden wurden als in Röhrenbrunnen (6.7 Prozent). Doch steigt bei den Kesselbrunnenproben die Häufigkeit des Colibefundes mit der Zunahme der Keimzahl nicht in dem. MaBe, wie es bei den Röhrenbrunnen der Fall ist. In Kesselbrunnenwasser mit hoher Keimzahl ist im Vergleich zu Röhrenbrunnen nicht nur relativ, sondern sogar absolut eine kleinere Zahl positiver Colibefunde zu verzeichnen. Das ist nur so zu erklären, daB in vielen Fällen in keimreichen Kesselbrunnenwässern der Colinachweis wohl wegen Überwucherns der Begleitbakterien nicht geglückt ist. Es dürfte demnach die Zahl colihaltiger Kesselbrunnenproben eine größere sein, als die Untersuchungen ergeben haben.

Wenn auch in Übereinstimmung mit den Untersuchungen anderer Autoren im allgemeinen die Häufigkeit des Colibefundes mit zunehmender Keimzahl sich mehrt, so darf doch nicht von einer absoluten RegelmäBigkeit dieses Parallelismus geredet werden. Von den 101 colinegativen Proben enthielten 28 über 100 Keime $=27.7$ Prozent und 12 über 1000 Keime $=11.9$ Prozent. Von den gesamten 120 Proben wurden unter 44 Proben, die eine Keimzahl über 100 enthielten nur 16 mal Colibazillen gefunden, d. h. eine Keimzahl über 100 ging nur in 36.4 Prozent der Fälle mit Colibefund einher. Andererseits wiesen drei der 19 colipositiven Proben eine Keimzahl unter 100 auf, d. h. in 15.8. Prozent der Untersuchungen wurden Colibazillen gefunden ohne gleichzeitige hohe Keimzahl. Der Keimzahlbefund an sich würde also nicht zu einer Beanstandung des Wassers in bakteriologischer Hinsicht geführt haben.

Wie wertvoll unter Umständen gerade die Coliuntersuchung eines zu Trinkzwecken bestimmten Wassers sein kann, ja allein der positive Colibazillenbefund einen berechtigten Verdacht gegen die Güte des Wassers erweckt, möchte ich an der Hand einiger Beispiele erläutern.

Hilgermann (57) weist ebenfalls in diesem Sinne auf den Wert der Coliuntersuchung hin und beschreibt fünf ansehauliche Fälle, in denen sich als Indikator stattgehabter Verunreinigung allein der Befund von Bacterium coli commune im Wasser erwies. Es ist anzunehmen, daB ähnliche Beobachtungen. häufiger gemacht werden. 
Was die eigenen Beobachtungen anlangt, so bandelt es sich zunächst um einen etwa $5^{\mathrm{m}}$ tiefen älteren Kesselbrunnen auf dem Hofe eines landwirtschaftlichen Betriebes, dessen Wasser seit vielen Jahren regelmäBig untersucht wurde und auf Grund der chemischen und bakteriologischen Untersuchung zu Beanstandungen keine Veranlassung gegeben hatte. Die Probeentnahmen fanden in der Regel im Frühjahr und Herbst statt. Geht man bis zum Jahre 1904 zurück, so finden sich im Wasser des erwähnten Brunnens bis zum Jahre 1907 Keimzahlen, die zwischen 7 und 75 schwanken. Thr Durschschnitt beträgt 38 pro Kubikzentimeter. Die aus einem auf dem Hausboden stehenden Reservoir geschöpften Proben ergaben 8 bis 150 , in Durschschnitt 54 Keime pro Kubikzentimeter. Quantitative Untersuchungen auf Bacterium coli fanden seit Ende 1906 statt, und z.war anfangs mit Mengen von $10 \mathrm{~cm}$, seit 1907 mit Mengen von 10 und $200 \mathrm{~cm}$. Coliähnliche Bakterien wurden nicht gefunden. Ebenso gleichmäBig und einwandfrei fielen die chemischen Untersuchungen aus. Ammoniak und salpetrige Säure ist nie gefunden worden, die Werte für Chlor und Oxydierbarkeit haben sich ziemlich gleichbleibend erhalten. Der Salpetersäuregehalt betrug etwa 30 bis $40^{\mathrm{mg}} \mathrm{im}$ Liter.

Bei einer Kontrolle am 10. IV. 08 nun fanden sich in einer untersuchten Menge von $200 \mathrm{cem}$ sowohl im Brunnenwasser als in der Reserroirprobe Colibazillen, nicht in $10 \mathrm{~cm}$. Die Keimzahlen betrugen $41 \mathrm{bzw}$. 65. Am 23. V. 08 wurde in Erfahrung gebracht, daB am 18. V. plötzlich Wassermangel eingetreten sei; der Wasserspiegel war so weit gesunken, daB der Saugkopf über Wasser stand. Die Beseitigung des Bodensehlammes hatte zwar eine alsbaldige Zunahme des Wasserquantums bewirkt, jedoch batte sich die Qualität des Wassers weiterhin verschlechtert, indem in $1^{\mathrm{cem}}$ des Brunnenwassers 4370, in $1^{\mathrm{cm}}$ des Reservoirwassers 2460 Keime und in beiden Proben in einer Menge von $10 \mathrm{cem}$ Colibakterien gefunden wurden. Die chemische Untersuchung hatte auch jetzt keine Anhaltspunkte für eine Veränderung des Wassers ergeben. Es sei weiter erwähnt, $\mathrm{dab}$ in einer $200^{\mathrm{ccm}}$ Probe eines aus einem Spalt der Schachtwandung $1.50^{\mathrm{m}}$ von der Sohle entfernt vorsprudelnden Wasserstrahls Colibazillen vorhanden waren; die Untersuchung von $10^{\mathrm{cm}}$ fiel negativ aus. Die Keimzahl dieser Probe betrug nur 11.

Es konnte also festgestellt werden, daß im Gegensatz zu früheren Untersuchungen das Wasser des Brunnens Colibakterien enthielt und bald darauf auch eine höhere Keimzahl aufwies. Daraufhin wurde das Wasser zu Trinkzwecken verboten.

Die weiteren Untersuchungen ergaben, da $B$ in nächster Nähe des Brunnenschachtes eine Sielleitung vorbeiführte, durch welche Regenwässer sowie die Spül- and Fäkalwässer der Ställe abflossen. Durch eine Be- 
schädigung dieser vor langer Zeit angelegten Leitung war eine Fäkalverunreinigung des umgebenden Erdreichs und auch des in nächster Nähe sich sammelnden Brunnenwassers denkbar. Es wurde in der Tat darauf festgestellt, dab das in einer Tiefe von etwa 2 m liegende Sielrohr verstopft war und das Sielwasser aus den undicht gewordenen Verbindungsstücken anscheinend gänzlich in das umgebende Erdreich einsickerte.

Es war also anzunehmen, daß diese Colibakterien aus dem Schmutzwasser der Sielleitung stammten, und $\mathrm{daB}$ somit eine Verunreinigung des Brunnens durch fäkalische Substanzen stattgefunden hatte.

Die Sielleitung wurde in eine Entfernung von $10^{\mathrm{m}}$ vom Brunnenrand rerlegt. Es wurde erwartet, daB allmählich eine Reinigung des verseuchten Irdreichs stattfände. Am 14. VII. ergab die Untersuehung des Wassers einen. Gehalt von 7100 Keimen und einen Colititer von $1 \mathrm{~cm}$. Am 3. IX. betrugen die Keimzahlen des Brunnenwassers 105, die des Reservoirwassers 89. In $200 \mathrm{~cm}$ beider Proben waren Colibazillen zu finden. Am 26. XI. wurden im Brunnenwasser 120 Keime, dagegen in $200 \mathrm{cem}$ keine Colibazillen mehr festgestellt. Am 22. VI. 09 betrug die Keimzahl 13 im Brunnenwasser und 38 im Reservoir. Auch jetzt wurden Colikeime nicht mehr gefunden.

Von einer Freigabe des Wassers zu Trinkzwecken wurde indessen bei der Beschaffenheit des Brunnens Abstand genommen, zumal einwandfreies Wasser vorhanden und infolge Steigerung des Verbrauchs eine Neuanlage beabsichtigt war.

Die Untersuchung einer bisher hygienisch einwandfreien Wasserversorgungsanlage also fällt chemisch und in bezug auf Keimzahl durchaus zufriedenstellend aus; dagegen werden in $200^{\mathrm{cem}}$ Colibazillen gefunden. Dieser Befund hat weitere Nachforschungen zur Folge, die eine Undichtigkeit eines bisher unbekannten, in nächster Năhe am Brunnenschacht vorbeifüh. renden Sielrohrs ergeben. Die Sielleitung wird verlegt. Nach einigen Monaten lassen sich in Mengen von $200^{\mathrm{cm}}$ des Brunnen wassers Colibazillen nicht mehr nachweisen.

In einem anderen Falle lagen die Verhältnisse folgendermaBen: Der tägliche Wasserbedarf von etwa $175 \mathrm{cbm}$ wird von zwei Bohrbrunnen gedeckt, ron denen der eine 1903 gebohrte eine Tiefe von $10^{\mathrm{m}}$, der andere $1905^{\prime}$ angelegte eine Tiefe von $12^{\mathrm{m}}$ hat. Bei dem älteren Brunnen beginnt der mit Kiesschüttung umgebene Filterkorb in einer Tiefe von $5 \cdot 40^{\mathrm{m}}$, bei dem zuletzt angelegten Brunnen in einer Tiefe von $8.80^{\mathrm{m}}$. Die Erdschichten bis zum Filterkorb bestehen aus weicher Moorerde (etwa $2.50^{\mathrm{m}}$ ) und aus tonigem und scharfem Sand. Die Entfernung beider Brunnell voneinander beträgt etwa $15 \mathrm{~m}$. Sie liegen in unmittelbarer 
Nähe des Maschinenhauses und Enteisenungsfilters. Wohnhäuser sind in weiter Entfernung nicht vorhanden.

Die bakteriologischen Ergebnisse seit Anfang 1906 bis Mitte 1908 stellten sich derart, daB die Keimzahl im Rohwasser zwischen 1 und 11, im Filtrat zwischen 1 und 78, im Reinwasserreservoir zwischen 3 und 81 schwankte. Der Durchschnitt der Untersuchungen dieser Zeit beträgt für Rohwasser 3.4, für Filtrat 20, für Reinwasserreservoir 31 Keime im Kubikzentimeter. Colibazillen wurden in den, zumeist in Mengen von $200^{\mathrm{cm}}$ untersuchten Proben nicht gefunden. Da die chemische Untersuchung außer dem leicht zu beseitigenden Eisengehalte auch günstig. ausfiel, so muBte das Wasser hygienisch als gut gelten.

Bei der am 12. XI. 08 vorgenommenen bakteriologischen Untersuchung nun wurden im Reinwasserreservoir, in dem Zapfhahnwasser des Hochreservoirs in Mengen von $200^{\mathrm{ccm}}$, im Zapfhahnwasser der Leitung auch in einer Menge von $10^{\mathrm{cm}}$ Colibazillen nachgewiesen. Die Keimzahlen betrugen 396, 546 bzw. 417, während im gemischten Rohwasser bei 8 Keimen in der untersuchten Menge von $200 \mathrm{~cm}$ keine Colibazillen gefunden wurden. Der chemische Befund wich jetzt und auch bei späterer Untersuchung gegen früher nicht ab.

Da die Keimarten auf den Gelatineplatten der hohe Keimzahlen aufweisenden Proben ziemlich übereinstimmten und die Rohwasseruntersuchung ein gutes Ergebnis hatte, so wurde eine Verunreinigung von der Filteranlage her als wahrscheinlich angesehen. Diese konnte wieder herrühren von baulichen Arbeiten, die im Maschinenraum und in einem Nebenraum des Filterraums vorgenommen wurden. Am 21. XI. fand eine nochmalige und umfangreiche Entnahme von Proben statt. Aus Staubund Erdeproben aus der Umgebung des Filterbehälters und überhaupt des Maschinenhauses wurden mehrfach Colibazillen gezüchtet.

Die Untersuchung der Wasserproben ergab wiederum die Anwesenheit des Bacterium coli in Mengen von $200^{\mathrm{cm}}$, in einer Zapf hahnprobe auch in Mengen von $10 \mathrm{com}$ Wasser, während die Keimzahlen niedriger im Vergleich zur vorausgegangenen, aber doch höher als der Durchschnitt der früheren Untersuchungen ausfielen. Bemerkenswert war aber der Colibefund in $200^{\mathrm{cm}}$ des Rohwassers. Da in wiederholten Untersuchungen nicht nur in dem Mischrohwasser, sondern auch in dem getrennten Rohwasser Colibazillen, am 14. I. 09 sogar einmal in einer Menge von $1^{\mathrm{ccm}}$ gefunden - wurden, so war nicht daran zu zweifeln, daB als eigentliche Quelle der Colibazillen beide Brunnen angesehen werden muBten. Die Colikeime gelangten mit dem Rohwasser auf die Filter und durch die Filter in die Leitung. Es konnten auch Colibazillen in Filtersandproben, die von der Oberfläche des Filters und aus einer Tiefe von $10^{\mathrm{cm}}$ ge- 
nommen waren, nachgewiesen werden. Die am 12. XI. 08 zuerst erhobenen Colibefunde wiederholten sich bei zahlreichen Untersuchungen. Die Keimzahlen des Rohwassers zeigten keinen Anstieg gegen früher an.

Es fragte sich nun hier wieder, waren diese Colibazillen als Zeichen einer fäkalen Verunreinigung anzusprechen? Die Möglichkeit lag vor. Das das Maschinen- und Filterhaus umgebende Gelände wurde vom Maschinisten als Gartenland bewirtschaftet. Durch Düngung dieses Geländes gelangten auch Colikeime in das Erdreich. Ein weiteres Vordringen dieser Keime zur Tiefe bis an das von dem Brunnen angesogene Wasser wurde einerseits durch die ziemlich durchlässigen Bodenschichten, andererseits durch die infolge gesteigerten Wasserverbrauchs vermehrte Inanspruchnahme bedingt, die eine gegen früher stärkere Absenkung von etwa $2^{\mathrm{m}}$ unter Terrain zur Folge hatte. Bemerkenswert war der Nachweis von Colibazillen in einer erbsengroßen Menge grauweißen Sandes, der mittels Fränkelschen Erdbohrers, etwa $50^{\mathrm{cm}}$ von dem $10^{\mathrm{m}}$ tiefen Brunnen entfernt, aus einer Tiefe von $3.30^{\mathrm{m}}$ heraufgeholt war. Eine Erdprobe aus einer Tiefe von $1^{\mathrm{m}}$ in der Nähe des $12^{\mathrm{m}}$ tiefen Brunnens enthielt nachweislich keine Colibazillen.

Das Ergebnis also ist: Nachweis von Colibazillen in einem frūher colifreien Rohwasser. Chemische Untersuchung und Keimzahl zeigten eine Veränderung des Wassers gegen frūher nicht an. Die auf Grund des Colibefundes angestellten Erhebungen ergeben die Möglichkeit einer stattgehabten fäkalischen Verunreinigung.

Die Keimzahlen allein hätten keine Handhabe gegeben, eine Veränderung des Wassers festzustellen.

In beiden mitgeteilten Beispielen handelt es sich mithin darum, daB durch den ermittelten Colibefund der Verdacht einer Fäkalverunreinigung des Brunnens rege wurde, welche dann durch die weiteren Resultate bestätigt werden konnte.

Zwei weitere den Wert der Coliuntersuchung bei der Beurteilung von Trinkwasser illustrierende Fälle verdanke ich der freundlichen Mitteilung und Überlassung von Herrn Prof. Dunbar. Das Quellengebiet der zunächst zu besprechenden Anlage besteht aus Wald und Wiesenland und ist unbewohnt. Einem aus Mauerwerk hergestellten Sammelsehacht flieBt das Wasser von 2 Seiten zu. Die Zuleitungen bestehen aus Steinzeugröhren, in quellenreichen Strecken aus Sickerrohr. Der ZufluB von Oberflächenwässern soll durch natürliche bzw. künstlich überdeckte, wasserundurchlässige Erdschichten abgehalten werden. Aus dem Sammelschacht fliebt das Wasser in einer guBeisernen Leitung zur Verbrauchsstelle. 
Die chemische Untersuchung ergab ein Wasser von ausgezeichneter Beschaffenheit. Auch in technischer Beziehung muBte die Anlage, die von sachverständiger Seite neu angelegt war, als einwandfrei gelten. Die Keimzahl konnte zur Beurteilung nicht verwendet werden, da die Proben wegen längeren Transportes erst 2 bis 3 Tage nach der Entnahme angesetzt werden konnten. Jedoch fanden sich in der übersandten Wasserprobe von 1 Liter Colibazillen, und zwar wiederholt in Mengen von $1.0 \mathrm{~cm}$. Dieser Befund erweckte den Verdacht einer fâkalen Verunreinigung, die im Laufe der weiteren Untersuchungen bestätigt wurde. Es stellte sich heraus, $\mathrm{da} B$ das Niederschlagsgebiet, aus dem das Wasser stammt, zum Teil gedüngt und mit Jauche begossen wurde. Hierdurch erklärten sich die bakteriologischen Befunde ohne weiteres. Es mußte angenommen werden, daB die Vorkehrungen zur Fernhaltung von Oberflächenverunreinigungen ungegenügend waren. Also allein der positive Colibefund führte dazu, ein Trinkwasser wegen fäkaler Verunreinigung zu beanstanden.

In einem weiteren Beispiele lagen die Verhältnisse folgendermaßen: Die Sammlung des Wassers erfolgt in einer auf einer Anhöhe gelegenen flachen Mulde, die einerseits hart von der etwa 4 bis $5^{\mathrm{m}}$ höher gelegenen Chaussee begrenzt wird, und auf deren anderer Seite ein Haus mit einem großen Misthaufen steht. Das Wasser flieBt in einem etwa $1 \frac{1}{2} \mathrm{~m}$ tief liegenden Sickerrohr zusammen und wird durch dieses in den Sammelschacht geleitet, von wo es an die Entnahmestellen gelangt. Der Misthaufen befand sich $6^{\mathrm{m}}$ entfernt von der Sickerrohrleitung.

Die Untersuchung ergab ein Wasser, das in chemischer und bakteriologischer Hinsicht durchaus zufriedenstellend war. Die Keimzahl betrug 5, Colibazillen wurden in $1000^{\mathrm{cm}}$ nicht gefunden. Das Vorhandensein der Dungstätte in $6^{\mathrm{m}}$ Entfernung von der Wasserversorgungsanlage wurde als bedenklich bezeichnet.

Eine zweite, einige Zeit später vorgenommene bakteriologische Untersuchung ergab denn auch ein ungünstiges Ergebnis, indem ein Colititer von 0.01 festgestellt wurde. Die Keimzahl lieB sich nicht verwerten, weil die Probe von auswärts eingesandt war. Wie eine Ortsbesichtigung zeigte, war zur Zeit der 2. Probeentnahme die obenerwähnte Mulde mit Wasser überstaut, das bis an den Misthaufen heranreichte und diesen auslaugte. Es unterliegt keinem Zweifel, daB auch in diesem Falle die Herkunft der in der Probe gefundenen Colibazillen auf den Misthaufen zurückzuführen ist. Die bedenkliche Beschaffenheit auch dieses Wassers konnte allein auf Grund der Coliuntersuchung erwiesen werden. 
Der Wert der Colidiagnose geht aus diesen Beispielen zweifellos hervor. Es ist allerdings ein Colibefund in einem Trinkwasser je nach der Herkunft des Wassers verschieden zu bewerten. Handelt es sich um ein Grundwasser im eigentlichen Sinne oder Quellwasser, so zeigt das Vorhandensein von Colibakterien stets eine Verunreinigung des Wassers irgendwelcher Art an. Diese kann zur Zeit der Untersuchung noch fortdauern oder vor mehr oder minder langer Zeit stattgefunden haben. $\mathrm{Ob}$ sie durch Warm- oder Kaltblütercoli erfolgt ist, ist praktisch nur insofern von Bedeutung, als ein Warmblütercolibefund eine erheblichere und bedenklichere Verunreinigung bedeutet. In jedem Fall müBte aber der Quelle der Verunreinigung nachgeforscht und diese, wenn möglich, beseitigt werden. Über den Grad der Verunreinigung und unter Umständen über die Dauer derselben kann die quantitative Colibestimmung Aufschlub geben.

Bei einem filtrierten Oberflächenwasser andererseits, sei es nun ein künstlich oder natürlich filtriertes, kann der Colibefund als soleher nicht zu einer Beanstandung des Wassers als Trinkwasser führen. Ein Oberflächenwasser enthält in der Regel Colibakterien und erfahrungsgemä $B$ werden diese durch die Filtration nicht vollständig aus dem Wasser entfernt. Hier ist nur die Colititerbestimmung von Bedeutung, da sie einen SchluB auf die Leistung der Filtration zuläBt. Die Zabl der Colibalkterien steht im allgemeinen in umgekehrtem Verhältnis zur Filterwirkung.

Die Untersuchung auf Colibakterien empfiehlt sich also stets bei der Kontrolle ron Wasserversorgungsanlagen; bei Grundwässern mit niedriger Keimzahl sind möglichst auch gröBere Mengen Wassers zu untersuchen, bei Wässern mit Colibefund ist der Colititer zu bestimmen.

\section{Znsammenfassung.}

1. Die bisher zum Nachweis ron Colibazillen rorgeschlagenen Methoden, insbesondere die Anreicherungsflüssigkeiten, gestatten das Auffinden der Colibakterien nur in einem gewissen Prozentsatz. Als besonders geeignet empfiehlt sich die $x$ nreicherung in 1 prozentiger Dextrosebouillon bei $37^{\circ}$.

2. Die Eijkmansche Methode reicht zum Nachweise ron Colibazillen in einem Wasser nicht aus und kommt nur als weitere Anreicherungsmethode in Betracht. Die Temperatur von $46^{\circ}$ schädigt das Wachstum der Colibazillen.

3. Der Colibacillus ist nicht ubiquitär. 
4. Der Befund von Colibazillen im Trinkwasser ist ein wertvoller Indikator für die Beschaffenheit des Wassers.

5. Es empfiehlt sich daher, bei der bakteriologischen Untersuchung ron Wasserversorgungsanlagen stets auch auf Colibakterien zu untersuchen.

6. Bei eigentlichen Grundwässern und Quellwässern läBt schon das Vorhandensein von Colibakterien im Wasser dieses als bedenklich erscheinen und sollte AnlaB zu Nachforschungen nach der Ursache der Verunreinigung geben. Der Colibefund ist häufig das erste Anzeichen einer Verunreinigung.

7. Bei gereinigten 0 berflächenwässern,natürlich und künstlich filtriertem Flubwasser oder Talsperrenwasser, ist die Colititerbestimmung wichtig für den Grad der Reinigung des Wassers. 


\section{Literatur-Verzeichnis.}

1. K. Saito, Über dic Bedeutung des Bacterium coli commune als Indikator für Vercnreinigung mit Fäkalien. Archiv für Hygiene. 1907. Bd. LXIII. S. 215.

2. Th. Smith, Über den Nachweis des Bacterium coli commnne im Wasser. Centralblatt für Bakteriologie. 1895. Bd. XVIII. S. 494.

3. v. Freudenreich, Über den Nachweis des Bacterium coli commune im Wasser und seine Bedeutung. Ebenda. 1895. Bd. XVIII. S. 102.

4. D. D. Jackson, A new solution for the presumptive test for bac. coli. Biological studies by the Pupils of William Thompson Sedgrick. Boston 1906.

5. Prescott und Winslow, Elements of Water Bacteriology. 2. Aufl. New York.

6. Sawin, Experience with lactose-bile medium for the detection of bact. coli in water. Journal of infectious diseases. Suppl. Nr. 3. Mai 1907. p. 30-32. Zitiert nach Prescott u. Winslow.

7. Weston a. Tarbett, Comparative results obtained by the use of lactosebile and dextrose-broth media for the detection of bac. coli in water. Ebenda. p. 39.

8. Parker, Amer. Joum. of Public. Health. 1908. Vol. IV. p. 19. Zitiert nach Stokes u. Stoner.

9. Stokes u. Stoner, Dextrose vs. lactose for detecting the colon bacillus. Centralblatt für Bakteriologie. 1909. Orig. Bd. LI. S. 459.

10. Lignières, Nourea moyen d'isolement du colibacille. Compt. rend. de la soc. de biolog. 1894. p. 200. Zitiert nach Kaiser.

11. M. Kaiser, Über die Bedeutung des Bacterium coli in Brunnenwasser. Archiv für Hygiene. 1905. Bd. LII. S. 121.

12. H. Chick, The distribution of Bact. coli commune. The Thompson-Yates Laboratories Report. III. - Ref. Hygien. Rundschau. 1902. Bd. XII. S. 647.

13. Bulir, Bedeutung und Nachweis des Bacterium coli im Wasser und eine Modifikation der Eijkmanschen Methode. Archiv für Hygiene. 1907. Bd. LXII. 
14. Loeffler, Der kulturelle Nachweis der Typhusbazillen in Fäces, Erde und Wasser mit Hilfe des Malachitgrüns. Deutsche med. Wochenschrift. 1906. S. 296.

15. Derselbe, Zum Nachweis und zur Differentialdiagnose der Typhusbazillen mittels der Malachitgrünnährböden. Ebenda. 1907. S. 1583.

16. F. Totsuka, Über den Nachweis des Bacterium coli in den Wässern und über den Wert dieses Nachweises für die hygien. Beurteilung. Inaug.-Dissertation. Greifswald 1908.

17. Harrison u. van der Leck, Äskulin-Gallensalznährboden zur Wasseranalyse. Centralblatt für Bakteriologie. 1909. Abt. II. Orig. Bd. XXII. S. 607.

18. A. Mac Conkey, Experiments on the differentiation and isolation from mixtures of the bacillus coli communis and bacillus typhosus by the use of sugars and the salts of bile. The Thampson Yates Laboratories Report. III. 41. 1900. Vgl. auch MIac Conkey u. Hill, Elbenda. Vol. IV. Part. I. p. 151. Zitiert nach Harrison a. van der Leck.

19. Winslow a. Hunnewell, A study of the distribation of the colon bacillus of Escherich and of the Sewage Streptococci of Houston in Polluted and Unpolluted Waters. Journal of Medical Research. 1902. Vol. VIII. p. 502.

20. Whipple, On the practical value of presumptive tests for bacillus coli in water. Technological Quarterly. 1903. Vol. XVI. 18. Zitiert nach Prescott und Winslow.

21. Marmann, Ein neues Verfahren zum quantitativen Nachweis des Bacterium coli im Wasser usw. Centralblatt für Bakteriologie. 1909. Bd. L. S. 26 .

22. Houston, Report of the Metropolitan water Board. Third annual Report. London 1908/09.

23. Winslow u. Nibecker, Studies on quantitative-variations in gas production in the fermentation-trube. Science. 1903. N. S. Vol. XVII. p. 375. Zitiert nach Winslow a. Prescott.

24. Longley u. Baton, Notes on the determination of B. coli in water. Journ. of infectious diseases. 1907. Vol. IV. p. 397.

25. Gage, Bacteriological studies at the Lawrence experiment Station, with special reference to the determination of $\mathrm{B}$. coli. Thirty-third annual report of the State board of health of Massachusetts for 1901, p. 397. Zitiert nach Prescott u. Winslow.

26. Clark a. Gage, On the value of tests for Bacteria of specific types as an index of pollation. Ebenda. 1902. Zitiert nach Bettencourt u. Borges.

27. Whipple, Quality of Kennebec river water. Water supply and irrigation paper. Nr. 198. N. S. - Geological survey. 1907. p. 167. Zit. nach Prescott u. Winslow.

28. Stoughton, Characteristics of colon bacilli and the value of the presumptive test. Journal of infectious diseases. 1905. Suppl. Nr. 2. p. 147.

29. Fuller u. Fergason, Concerning tests for B. coli commune in water. Ebenda. 1905. Suppl. Nr. 2. p. 142.

30. Winslow u. Phelps, nicht veröffentlicht. Mitgeteilt bei Prescott und Winslow.

31. Jachson, The use of lactose-bile medium in water analysis. Journal of infectious diseases. 1907. Suppl. Nr. 3. p. 30. 
32. Sawin, Experience with lactose-bile medium for the detection of B. coli in water. Journal of infectious diseases. 1907. Suppl. Nr. 3. p. 33.

33. Rothberger, Differentialdiagnostische Untersuchungen mit gefärbten Nährböden. Centralblatt für Bakteriologie. 1898. Abt. I. Bd. XXIV. S. 513.

34. Makgill, The neutral-red reaction as a means of detecting bacillus coli in water-su pplies. Journal of Hygiene. 1901. I. p. 430.

35. Savage, Nentral red in the rontine bacteriological examination of water. Ebenda. 1901. I. p. 437.

36. Brann, Lue rouge neutre et le diagnostic rapide de la souillure des eaux de boisson par le colibacille. Bulletin de l'Institut Pasteur. 1906. T. IV. p. $\overline{5} 61$. Zit. nach Prescott u. Winslow.

37. Irons, Neutral red in the routine examination of water. Journ. of Hyg. 1902. II. p. 314.

38. Gage u. Phelps, Notes on B. coli u allied forms, with special reference to the neutral red reaction. Transactions of the Am. Publ. Health Assoc. 1902 Meeting. 1903. Vol. XXVIII. p. 402. Zitiert nach Prescott a. Winslow.

39. Grünbaù u. Hume, British Medical Journal. 1902. p. 1473.

40. Jordan, The kinds of bacteria found in river water. Journ. of Hygiene. 1903. Vol. III.

41. Stokes, A simple test for the rontine detection of the colon bacillus in drinking water. Journal of infectious diseases. I. p. 431.

42. Vincent, Sur la signification du „bacillus coli“ dans les eaux potables. Annales de l'Instiut Pasteur. 1905. 'T. XIX. p. 233.

43. Rodet, De l'importance de la température dans la détermination des espèces microbiennes etc. Compt. rend. de la soc. de biologie. 1889. Nr. 26. Ref. Centralblatt für Bakteriologie. Bd. VI. S. 500.

44. Eijkman, Die Gärungsprobe bei $46^{\circ}$ als Hilfsmittel bei der Trinkwasseruntersuchung. Centralblatt für Bakteriologie. 1904. Bd. XXXVII. Orig. S. 742.

45. Christian, Zum Nachweis fäkaler Verunreinigung von Trinkwasser Archiv für Hygiene. 1905. Bd. LIV. S. 386.

46. Neumann, Der Nachweis des Bacterium coli in der Außenwelt unter $\mathrm{Zu}$ hilfenahme der Eijkmanschen Methode. Ebenda. 1906. Bd. LIX. S. 174.

47. Thomann, Zum Nachweis des Bacterium coli commune im Wasser vermittelst der Eijkman schen Methode. Hygienische Rundschau. 1907. Bd. XVII. S. 857 .

48. Nowack, Untersuchungen über die Zuverlässigkeit der Eijkman schen Probe. Mitteilungen aus der Königl. Prüfungsanstalt für Wasserversorgung uud Abwässerbeseitigung zu Berlin. 1907. Hft. IX. S. 197.

49. Kruse, Beiträge zur Hygiene des Wassers. Diese Zeitschrift. Bd. LIX. 1908. S. 6.

50. Vincent, Die quantitative Bestimmung des Bacterium coli im Trinkwasser. $L^{\prime}$ Hygiène générale et appliquée. 1909. T. IV. Nr. 2.

51. Mallannah, nicht veröffentlicht.

52. Worthmann, Untersuchungen über die Eijkmansche Probe und ein eigenartiges, Gärung erregendes Bacterium. Mitteilungen aus der Königl. Prüfungs- 
anstalt für Wasserversorgung und Abwässerbeseitigung zu Berlin. 1907. Hft. IX. S. 185.

53. Mordberg, Zar Biologie des Bacterium coli. Mikrobiolog. Gesellschaft zu St. Petersburg. Sitzung rom 11./24. Mai 1907. Ref. Centralblatt für Bakteriologie. 1908. Bd. XLI. S. 796.

54. Lange, Über Bacterinm coli commune. Verhandl. deutscher Naturforscher und Ärzte. 79. Versammlung zu Dresden. 15. bis 21. Sept. 1907. 2. Teil. 2. Hälfte. S. 513. 1908 .

55. Reinsch, Bericht des chemischen Untersuchungsamtes der Stadt Altona.

56. Federolf, Über den Nachweis des Bacterium coli im Wasser durch die Fällungsmethode. Archiv für Hygiene. 1909. Bd. LXX. S. 311.

57. Hilgermann, Der Wert des Bacillus coli-Befundes zur Beurteilung der Reinheit eines Wassers. Der Wert der Eijkmanschen Gärungsprobe. Klin. Jahrb. 1909. Bd. XXII. S. 315 .

58. v. Benczur, Kleiner Beitrag zur Frage der Identität des Typhus- u. Colibacillus. Centralblatt für Bakteriologie. 1909. I. Bd. XLVIII. S. 275.

59. v. Drigalski u. Conradi, Über ein Verfahren zum Nachweis der Typhusbazillen. Diese Zeitschrift. 1902. Bd. XXXIX. S. 283.

60. Endo, Über ein Verfahren zum Nachweis der Typhusbazillen. Centralblatt für Bakteriologie. Orig. 1904. Bd. XXXV. S. 109.

61. Guth, Zum Nachweis von Typhus- u. Paratyphusbakterien. Ebenda. Orig. 1909. Bd.LI. S. 190 .

62. Klinger, Über neuere Methoden zum Nachweis des Typhusbacillus in den Darmentleerungen. Arbeiten aus dem Kaiserl. Gesundheitsamte. 1906. Bd. XXIV. S. 35 .

63. Rivas, Contribution to the differentiation of bacillus coli communis from allied species in drinking water. The Journ. of Medical Research. 1908. Vol. XVIII. p. 81.

64. Gage, Significance of the numbers of bacteria in water and sewage developing at different temperatures. Thirty-eight annual report of the Massachuset State board of health. 1906. p. 325-349.

65. Ingelfinger, Bericht der Verhandl. der Gesellschaft deutscher Naturf. u. Arzte. 79. Versammlnng zu Dresden. 15. bis 21. Sept. 1907. II. 1. S. 573.

66. Marmann, Bericht über die Tätigkeit des bakteriologischen Untersuchungsamtes zu Göttingen im Jahre 1907/08. Hygien. Rundschau. 1908. S. 1013.

67. Schottelius, Die Bedeutung der Darmbakterien für die Ernährang. Arch. ür Hygiene. 1908. Bd. LXVII.

68. Dyar a. Keith, Notes on normal intestinal bacilli of the horse and of certain other domesticated animals. Technology Quarterly. 1893. VI. p. 256 . Zit. nach Prescott u. Winslow.

69. Fremlin, Vergleichende Studien an Bacterium coli commune verschiedener Provenienz. Archiv für Hygiene. 1893. Bd. XIX. S. 295.

70. Brotzu, Sulla desinfezione del canale intestinale. Ann. del l'inst. d'igiene sperimentale della Università di Roma. IV. p. 427. - Ref. Centralblatt für Bak. teriologie. 1895. Bd. XVII. S. 726. 
71. Kern, 1896, zitiert nach Eyre.

72. Belitzer, 1899, zitiert nach Prescott u. Winslow.

73. Hoag, 1899, zitiert nach Ferreira, Horta u. Paredes.

74. Houston, Report on the bacteriological examination etc. Supplement to thirty-third annual report of the Local Governement board containing the report of the medical officer for $1903 / 04$.

75. Moore n. Wright; A comparison of B. coli communis from different species of animals. Journal of the Boston society of Medical sciences. 1900. IV. p. 175. Zitiert nach Prescott u. Winslow. - Ferner: Preliminary observations on B. coli communis from certain species of animals. Scienre. N. S. XV. p. 372. Ref. Centralblatt für Balcteriologie. Abt. I. 1902. Bd. XXXI. S. 307.

76. Eyre, On the distribution of bacillas coli in nature. Lancet. 1904. p.648.

77. Ferreira, Horta u. Paredes, Recherches sur le b. coli de l'intestin des mammifères et des oiseanx. Archivos do real instituto bacteriologico camara pestana. Lissabon 1908. T. II. p. 203.

78. Johnson, Isolation of bacillus coli communis from the elementary tract of fish and the significance thereof. Journ. of infect. diseases. 1904. I. p. 384.

79. A myot, Is the colon bacillus a normal inhabitant of the intestines of fishes? Transactions of the americ. public. health association. 1901 meeting. XXVII. p. 402. Zitiert nach Prescott u. Winslow.

80. Kister, nicht veröffentlicht.

81. Moore u. Wright, Preliminary observation on B. coli commune from certain species of animals. Science. N. S. XV. p. 372. Zitiert nach Prescott $u$. Winslow.

82. Soper, Med. News. Vol. LXXXVI. Nr. 6.

83. Ayers, B. coli in market oysters. Biol. stud. of the pupils of W. Thomson Sedgwiek. Boston 1906. p. 300. Ref. Centralblat für Bakteriologie. 1907. Bd. XL. p. 519.

84. Houston, 4. Report of the royal Commission on senage disposal. 1904.

85. Klein, Ebenda.

86. Fuller, The flora of the intestinal of the oysters. Zitiert im Report of the royal Commission on sewage disposal.

87. Browne, 4 Report of the royal Commission on sewage disposal. 1904 p.192.

88. Schwarz, nicht veröffentlicht.

89. Bettencourt u. Borges, Recherches sur le B. coli des vertébrés inférieurs et des céréales. Archives do real instituto bacteriologico camara pestana. Lissabon 1908. T. II. Fasc. II. p. 221.

90. Klein u. Houston, Preliminary account of the results of a bacterioscopic analysis 'of different cereals and food-stuffs. Supplement to the Twenty-ninth annual report of the Local government board. Report of the medical officer for 1899/1900. p, 593.

91. Winslow $u$. Walker, Note on the fermentative reactions of the $B$. coli groupe. Science. N. S. T. XXVI. p. 797. Zitiert nach Prescott u. Winslow.

92. Ressel, Über fäkale Verunreinigungen auf Obst u. Gemüse. Dissertation. Berlin 1907. Ref. Hygien. Centralbl. 1908. Bd. IV. S. 16. 
93. Prescott, On certain precautions required in making and interpreting the so-called "Colon Test" for potable waters. Medicine. 1903. T. XI. p. 20. Zitiert nach Prescott n. Winslow.

94. Prescott u. Smith, Mixter u. Gunn, The oceurence of organisms of sanitary significance on grains. Biological studies by the pupils of William Thompson Sedgwick. Boston 1906. p. 208. Zitiert nach Bettencourt a. Borges.

95. Gordan, Bakteriologische Untersuchungen zur Beurteilung von Kleien nach ihrer Neigung zur Schimmelbildang. Die landwirtschaftliche Versuchsstation. Bd. IX. S. 73. Ref. Centralblatt für Balcteriologie. 1904. Abt. II. Bd. XIII. S. 561.

96. Düggeli, Die Bakterienflora gesunder Samen und daraus gezogener Keimpłänzchen. Centralblatt für Balcteriologie. 1904. Abt. II. Bd. XII. S. 602.

97. Barthel, Bidrag till kännedomen om mjölksysebakteriernas förekomst och utbredning utom mjölken. Ref. Centralblatt f. Bakteriologie. 1906. Abt. II. Bd. XVI. S. 550 .

98. Papasotirin, Untersuchungen über das Vorkommen des Bacterium coli im Teig, Mehl und Getreide, nebst einigen Bemerkungen über die Bedeutung des Bacterium coli als Indikator für Verunreinigung von Wasser mit Fäkalien. Archiv für Hygiene. 1902. Bd. XLI. S. 204.

99. Sonnen, Bijdrage tot de Kennis van de cerspreiding van smetstoffen in Amsterdam. Dissertation. Amsterdam 1908.

100. Bergbaus, Über die Verbreitung von Infektionsstoffen. Arch. f. Hygiene. 1907. Bd. LXI. S. 164.

101. Pfuhl, Beitrag zur Bedeutung der Kleidung als Infektionsvermittler. Allgem. med. Centralzeitung. 1896.

102. Brunner, Eine Beobachtang von Wandinfektion durch das Bacterium coli commune. Centralblatt für Balteriologie. 1894. Bd. XVI.

102a. Henke, Beitrag zur Verbreitung des Bacterium coli commune in der AuBenwelt nsw. Centralblatt für Bakteriologie. 1894.

103. Heubner, Über septische Infektionen in Säuglingsalter. Verhandlungen der Gesellschaft der Charité-Ärzte. Berliner klin. Wochenschrift. 1895. Nr. 27.

104. Solowieff, Bakteriolog. Untersuchung des Staubes der Spitalzenghäuser. Wratsch. 1895. Zitiert nach Kolle-Wassermanns Handbuch.

105. Zieleniew, Über bakterielle Verunreinigung der Spitalgeräte. Wratsch. 1895. Zitiert nach Kolle-Wassermanns Handbuch.

106. Cacace, Die Bakterien der Schule. Centralblatt für Bakteriologie. 1901.

107. Lehmann, Die Methoden der praktischen Hygiene. 1890.

108. Miquel, Manual pratique d'analyse bactériologique des eaux. Paris 1891. Zitiert nach Prescott u. Winslow.

109. Kruse, Zur hygienischen Bęurtẹilung des Wassers. Diese Zeitschr. 1894. Bd. XVII. S. 53 .

110. Loeffler, Unification des procédés d'analyse bactériologique des eaux. Auf dem XIII. int. Kongr. f. Hyg. u. Demogr zu Brüssel. Compt. rend. du Congrès. T. II.

111. Gärtner, Über Methoden, die Möglichkeit der Infektion eines Wassers zu beurteilen. Festschrift zur 100jährigen Stiftungsfeier des medizin.-chirurg. Friedrich Wilhelm-Instituts. Berlin 1895. 
112. Burri, Nachweis von Fäkalbakterien im Trinkwasser. Hygien. Rundschau. 1895. S. 49 .

113. Abba, Sulla presenza del bacillus coli nelle acque potabili, e sopra un metodo per metterlo in evidenza. Le Riforma medica. 1895. Vol. XI. p. 302 . Zitiert nach Prescott a. Winslow.

114. Refik, Sur les divers types de coli-bacille des eaux. Annales de l'Institut Pasteur. 1896. T. X. p. 242.

115. Poujol, Sur la présence très fréquent du Bact. coli dans les eanx naturelles. Compt. rend. de la soc. de biol. 1897.

116. Moroni, La presenza de bacillus coli commune nelle acque. La Riforma medica. 1899. Vol. XV. Zitiert nach Prescott u. Winslow.

117. Levy a. Brans, Zür Hygiene des Wassers. Archiv für Hygiene. 1899. Bd. XXXVI. S. 178.

118. Weissenfeld, Der Befund des Bacterium coli im Wasser und das Tierexperiment sind keine brauchbaren Hilfsmittel für die hygienische Beurteilung des Wassers. Diese Zeitschrift. 1900. Bd. XXXV. S. 80.

119. Péré, Contribution à l'étude des eaux d'Alger. Annales de l'Inst. Pasteur 1891. Nr. 2. p. 79.

120. Dunbar, Untersuchungen über den Typhusbacillus und den Bacillus coli commune. Diese Zeitschrift. 1892. Bd. XII. S. 484.

121. Schardinger, Beitrag zur hygien. Beurteilung des Trinkwassers. Centralblatt für Bakteriologie. 1894. Bd. XVI. S. 853.

122. Guirand, Note sur la présenee des microbes pathogènes sur les légumes et produits maraîchers. Compt. rend. de la soc. de biol. 1896. Zitiert nach KolleWassermanns Handbuch.

123. $\mathrm{Mez}$, Mikroskopische Wasseranalyse. Berlin 1898.

124. Kübler u. Neufeld, Über einen Befund von Typhusbazillen im Brunnenwasser. Diese Zeitschrift. 1899. Bd. XXXI. S. 133.

125. Jordan, Über die Entwicklung des Bacterium coli commune in Wasser. Centralblatt für Bakteriologie. 1900. Bd. XXVII. S. 679.

126. Clark u. Gage, Die Bedeutung des Erscheinens von Bact. coli commune im filtrierten Wasser. Centralblatt für Bakteriologie. 1900. Bd. XXVII. S. 678.

127. Houston, 2. Report of the Comm. on sewage disposal. London 1902. p. 25 und 135 .

128. Pfaundler, Bacterium coli commune, Escherich u. Pfaundler. Handbuch ron Kolle.Wassermann. Bd. II.

129. Meusburger u. Rambousek, Beitrag zum bakteriologischen Nachweis von Trinkwasserverunreinigungen anläBlich infektiöser Erkrankungen. Centralblatt für Bakteriologie. Orig. 1902. Bd. XXXII. S. 477.

130. Petruschky a. Pusch, Bacterium coli commune als Indikator für Fäkalverunreinigung von Wässern. Diese Zeitschrift. 1903. Bd. XIIII. S. 304.

131. Hirschbruch u. Schwer, Hygien. Rundschau. Bd. XIII. S. 864.

132. Winslow, Die Verteilung des Bacterium coli commune in natürlichen Gewässern. Ref. Centralblatt für Balcteriologie. 1901. Abt. I. Refer. Bd. XXXI. S. 306. 
304 W. Fromme: Utber Colibakterien im Trinkwasser.

133. Savage, The significance of bacillus coli in drinking water. Journal of Hygiene. 1903. T. II. p. 328.

133a. Vincent, Sur la signification du „Bacillus coli“ dans les eanx potables. Annales de l'Institut Pasteur. 1905. T. XIX. p. 233.

134. Seige u. Gundlach, Die Typhusepidemie in W. im Herbst 1903. Arbeiten aus dem Kaiserl. Gesundheitsamte. 1906. Bd. XXIV. S. 77.

135. Venema, Über eine Anreicherung von Bacterium coli in Wasser. Centralblatt für Balteriologie. 1906. Bd. XL. S. 600 .

136. Parietti, Metodo di ricerca de bacillo del tifo nelle acque potabili. Riv. d'igiene e sanità publica. 1890. Zitiert nach Kaiser, a. a. $O$. 